\title{
Rapid Disinhibition by Adjustment of PV Intrinsic Excitability during Whisker Map Plasticity in Mouse S1
}

\author{
Melanie A. Gainey, Joseph W. Aman, and Daniel E. Feldman \\ Department of Molecular \& Cell Biology, Helen Wills Neuroscience Institute, University of California, Berkeley, Berkeley, California 92093-3200
}

\begin{abstract}
Rapid plasticity of layer (L) 2/3 inhibitory circuits is an early step in sensory cortical map plasticity, but its cellular basis is unclear. We show that, in mice of either sex, $1 \mathrm{~d}$ whisker deprivation drives the rapid loss of L4-evoked feedforward inhibition and more modest loss of feedforward excitation in L2/3 pyramidal (PYR) cells, increasing the excitation-inhibition conductance ratio. Rapid disinhibition was due to reduced L4-evoked spiking by L2/3 parvalbumin (PV) interneurons, caused by reduced PV intrinsic excitability. This included elevated PV spike threshold, which is associated with an increase in low-threshold, voltage-activated delayed rectifier (presumed Kv1) and A-type potassium currents. Excitatory synaptic input and unitary inhibitory output of PV cells were unaffected. Functionally, the loss of feedforward inhibition and excitation was precisely coordinated in L2/3 PYR cells, so that peak feedforward synaptic depolarization remained stable. Thus, the rapid plasticity of PV intrinsic excitability offsets early weakening of excitatory circuits to homeostatically stabilize synaptic potentials in PYR cells of sensory cortex.
\end{abstract}

Key words: feedforward inhibition; homeostasis; intrinsic excitability; plasticity; PV neuron; sensory cortex

Significance Statement

Inhibitory circuits in cerebral cortex are highly plastic, but the cellular mechanisms and functional importance of this plasticity are incompletely understood. We show that brief $(1 \mathrm{~d})$ sensory deprivation rapidly weakens parvalbumin $(\mathrm{PV})$ inhibitory circuits by reducing the intrinsic excitability of PV neurons. This involved a rapid increase in voltage-gated potassium conductances that control near-threshold spiking excitability. Functionally, the loss of PV-mediated feedforward inhibition in L2/3 pyramidal cells was precisely balanced with the separate loss of feedforward excitation, resulting in a net homeostatic stabilization of synaptic potentials. Thus, rapid plasticity of PV intrinsic excitability implements network-level homeostasis to stabilize synaptic potentials in sensory cortex.

\section{Introduction}

Parvalbumin (PV) inhibitory circuits are highly plastic to altered sensory experience and contribute to receptive field plasticity in sensory cortex (Froemke, 2015). PV circuit plasticity is evident after just 1-2 d of visual or auditory deprivation or $3 \mathrm{~d}$ of whisker deprivation, and thus is an early step in cortical plasticity. In layer (L) 2/3, deprivation reduces PV-mediated inhibition, which can increase sensory-evoked responses in pyramidal (PYR) cells and enable subsequent Hebbian plasticity (Gambino and Holtmaat,

Received Dec. 25, 2017; revised March 27, 2018; accepted April 10, 2018.

Author contributions: M.A.G., J.W.A., and D.E.F. designed research; M.A.G. and J.W.A. performed research; M.A.G., J.W.A., and D.E.F. analyzed data; M.A.G. and D.E.F. wrote the paper.

This work was supported by National Institutes of Health Grants 1R01-NS-073912 and F32-NS-087893 (to M.A.G.), and a National Science Foundation Graduate Research Fellowship (to J.W.A.). We thank Brooke Angel and Dhruv Malik for histology and solution making.

Correspondence should be addressed to Daniel E. Feldman, 142 Life Sciences Addition, Mail Code 3200, Departement of Molecular \& Cell Biology, University of California, Berkeley, Berkeley, CA 92093-3200. E-mail: dfeldman@berkeley.edu.

DOI:10.1523/JNEUROSCI.3628-17.2018

Copyright $\odot 2018$ the authors $\quad 0270-6474 / 18 / 384749-13 \$ 15.00 / 0$
2012; Donato et al., 2013; Kuhlman et al., 2013; Li et al., 2014; Froemke, 2015; Resnik and Polley, 2017). Disinhibition may also implement rapid homeostasis to stabilize and maintain mean PYR firing rate for several days before the onset of ocular dominance or whisker map plasticity (Hengen et al., 2013; Li et al., 2014; Barnes et al., 2015; Gainey and Feldman, 2017; Turrigiano, 2017).

Despite its functional importance, the cellular mechanisms for rapid disinhibition are incompletely understood. Best studied are structural changes, including the loss of inhibitory synapses and structural remodeling of GABAergic axons (Marik et al., 2010; Keck et al., 2011; Chen et al., 2012; van Versendaal et al., 2012; Chen and Nedivi, 2013). Deprivation can also functionally weaken excitatory input synapses and inhibitory output synapses of PV cells (Maffei et al., 2004; Jiao et al., 2006; House et al., 2011; Kuhlman et al., 2013; Xue et al., 2014; Sun et al., 2016). In contrast, whether experience alters the intrinsic excitability of PV neurons has been less clear. Molecular pathways exist for activitydependent regulation of PV intrinsic excitability, but whether experience engages these mechanisms to rapidly alter intrinsic 
excitability in vivo is unknown (Li et al., 2011; Dehorter et al., 2015). Mechanisms for PV circuit plasticity have been mostly studied after long-term activity manipulation (days or weeks; Jiao et al., 2006; Sun, 2009; House et al., 2011; Kätzel et al., 2011; Xue et al., 2014), and, thus, the mechanisms that underlie rapid disinhibition remain murky.

We examined the mechanisms for rapid disinhibition in $\mathrm{L} 2 / 3$ of somatosensory cortex (S1). In rats, 5-7 d of whisker deprivation reduces feedforward and recurrent inhibition in L2/3 PYR cells, mediated by weakening excitatory synapses onto PV neurons (House et al., 2011; Shao et al., 2013). Disinhibition also occurs in rats after $3 \mathrm{~d}$ of deprivation, where it is thought to homeostatically stabilize whisker-evoked firing in L2/3 PYR cells, but the mechanisms for this rapid disinhibition are unknown (Li et al., 2014). Here, we examined rapid disinhibition after $1 \mathrm{~d}$ of whisker deprivation in mice, which matches the briefest period of deprivation known to induce disinhibition in visual cortex (Kuhlman et al., 2013). One day of deprivation robustly weakened feedforward L4-L2/3 inhibition in L2/3 PYR cells, due to reduced L2/3 PV neuron spiking. Unlike in prior studies of PV circuit plasticity, this was not due to reduced synaptic drive onto PV cells, but instead was caused by rapid reduction of PV intrinsic excitability. This was mediated by increased voltage-activated potassium currents that elevated the PV spike threshold, reducing near-threshold excitability. Functionally, rapid disinhibition preserved net L4-evoked peak synaptic responses in L2/3 PYR cells, suggesting that the rapid plasticity of PV intrinsic excitability acts to homeostatically stabilize sensory responses in the PYR network during ongoing changes in sensory use.

\section{Materials and Methods}

Procedures were approved by the University of California, Berkeley Animal Care and Use Committee and followed National Institutes of Health guidelines. PV-IRES-Cre mice (catalog \#008069, The Jackson Laboratory; https://www.jax.org/strain/008069; Hippenmeyer et al., 2005) were crossed with Cre-dependent TdTomato reporter (Ai14) mice (catalog \#007914, The Jackson Laboratory; https://www.jax.org/strain/007914; Madisen et al., 2010) to generate PV-Cre;tdTomato offspring. Layer 4 optogenetics experiments were performed in Scnnla-Tg3-Cre mice (https://www.jax.org/strain/009613). Mice were housed as litters in standard cages. For whisker deprivation, the right D-row whiskers (D1-D6 and gamma) were plucked under transient isoflurane anesthesia, $24 \pm$ $2 \mathrm{~h}$ before slice preparation. Sham-plucked littermates underwent anesthesia but not plucking.

\section{Slice preparation}

Postnatal day 18 (P18) to P21 mice of either sex were anesthetized with isoflurane and decapitated. Brain slices were prepared using a Leica VT1200S vibratome in chilled, oxygenated, low-sodium, low-calcium Ringer's solution (in mM: $85 \mathrm{NaCl}, 75$ sucrose, $25 \mathrm{D}-(+)$-glucose, 4 $\mathrm{MgSO}_{4}, 2.5 \mathrm{KCl}, 1.25 \mathrm{Na}_{2} \mathrm{HPO}_{4}, 0.5$ ascorbic acid, $25 \mathrm{NaHCO}_{3}$, and 0.5 $\left.\mathrm{CaCl}_{2}, 320 \mathrm{mOsm}\right)$. Cortical slices $(350 \mu \mathrm{m})$ were cut from the left hemisphere in the "across-row" plane, oriented $50^{\circ}$ toward coronal from the midsagittal plane and $35^{\circ}$ from vertical. Using this plane, each slice contains one column from each whisker row $\mathrm{A}-\mathrm{E}$, and within-column circuits are largely preserved (Finnerty et al., 1999; Allen et al., 2003). Slices were transferred to standard Ringer's solution (in mм: $119 \mathrm{NaCl}, 26.2$ $\mathrm{NaHCO}_{3}, 11 \mathrm{D}-(+)$-glucose, $1.3 \mathrm{MgSO}_{4}, 2.5 \mathrm{KCl}, 1 \mathrm{NaH}_{2} \mathrm{PO}_{4}, 2.5 \mathrm{CaCl}_{2}$, $300 \mathrm{mOsm}$ ) for $30 \mathrm{~min}$ at $30^{\circ} \mathrm{C}$ and then were kept at room temperature until recording $(0.5-7 \mathrm{~h})$.

Slice electrophysiology and L4-evoked synaptic responses. Recordings were made at $30-31^{\circ} \mathrm{C}$ in standard Ringer's solution. Barrel columns were identified by transillumination at $4 \times$, and visually guided patching was performed using infrared differential interference contrast optics at $40 \times$. L2/3 PYR cells were identified by soma shape, and were located $\sim 100-240 \mu \mathrm{m}$ below the L1-L2 boundary, within $\sim 100 \mu \mathrm{m}$ tangentially of column center. PV neurons were identified by tdTomato fluorescence (530-550 nm bandpass excitation, 575-625 nm emission; Dage-MTI camera). PYR cell recordings were made in PV-Cre;tdTomato or C57BL/6 mice (https://www.jax.org/strain/000664).

All recordings were made in $\mathrm{L} 2 / 3$ of $\mathrm{D}$-row barrel columns, with the NMDA receptor antagonist $50 \mu \mathrm{M}$ D-AP5 in the bath. Whole-cell recording was performed with 3-5 $\mathrm{M} \Omega$ pipettes using a Multiclamp 700B Amplifier (Molecular Devices) with $2 \mathrm{kHz}$ low-pass filtering and $7-10 \mathrm{kHz}$ digitization. L4-evoked synaptic responses were elicited using $200 \mu \mathrm{s}$ current pulses delivered via a bipolar stimulating electrode $(115 \mu \mathrm{m}$ tip spacing, FHC) placed in the center of the D barrel in L4. The interstimulus interval was $10 \mathrm{~s}$. For input-output curves, the EPSC threshold (E $\theta$ ) was defined as the minimal stimulation current that evoked an EPSC in five consecutive sweeps. For L2/3 PYR cells, the $\mathrm{E} \theta$ was determined individually for each cell. For PV cells, E $\theta$ was defined as the average E $\theta$ measured for two cocolumnar L2/3 PYR cells.

Voltage-clamp recordings of synaptic currents used cesium gluconate internal solution (in mM: 108 D-gluconic acid, $108 \mathrm{CsOH}, 20$ HEPES, 5 tetraethylammonium (TEA)-Cl, $2.8 \mathrm{NaCl}, 0.4$ EGTA, 4 MgATP, 0.3 NaGTP, 5 BAPTA, and 5 QX-314 bromide, pH 7.2, 295 mOsm). The holding potential $\left(V_{\text {hold }}\right.$ ) was corrected for the liquid junction potential $(12 \mathrm{mV})$. Series resistance (Rseries) was monitored in each sweep and was compensated by $40-80 \%$. Cells whose input resistance (Rinput) changed $>30 \%$ throughout recording were excluded from analysis. PYR cells with a resting membrane potential $\left(V_{\text {rest }}\right)$ that was more depolarized than $-60 \mathrm{mV}$ were discarded. L4-evoked EPSCs and IPSCs were separated by recording at $V_{\text {hold }}=-68$ and $0 \mathrm{mV}$, respectively, which correspond to the chloride equilibrium potential $\left(E_{\mathrm{Cl}}\right)$ and the glutamate receptor reversal potential $\left(E_{\mathrm{AMPA}}\right)$. Currents were converted to conductances using standard methods (Wehr and Zador, 2003; House et al., 2011). Integrated synaptic conductance was quantified in a window 3-23 ms after the stimulus.

Current-clamp recordings were made using $\mathrm{K}$ gluconate internal solution (mM: $116 \mathrm{~K}$ gluconate, $20 \mathrm{HEPES}, 6 \mathrm{KCl}, 2 \mathrm{NaCl}, 0.5 \mathrm{EGTA}, 4$ MgATP, 0.3 NaGTP, and $5 \mathrm{Na}_{2}$ phosphocreatine, pH 7.2, $295 \mathrm{mOsm}$ ). Series resistance artifacts were corrected by bridge balance. In PV cells, postsynaptic potentials (PSPs) were measured from a baseline of -68 $\mathrm{mV}$, the mean $V_{\text {rest }}$ of L2/3 PV neurons. PSP amplitude was quantified in a $1.8 \mathrm{~ms}$ window at the peak. In PYR cells, we measured L4-evoked PSPs from $V_{\text {rest }}$ or from an estimated synaptic membrane potential $\left(V_{\text {syn }}\right)$ of $-55 \mathrm{mV}$ achieved by somatic current injection. For the latter case, because cells in current clamp are not spatially isopotential, we performed a separate calibration experiment to estimate the difference between somatic membrane potential $\left(V_{\text {soma }}\right)$ and $V_{\text {syn }}$ during somatic current injection in these conditions. To do this, we recorded using modified $\mathrm{K}$ gluconate internal with Nernst potential for chloride of $-50 \mathrm{mV}$, and found that somatic depolarization to $-44.3 \pm 1.3 \mathrm{mV}$ was necessary to reverse pharmacologically isolated $\mathrm{GABA}_{\mathrm{A}}$-mediated IPSPs in current clamp ( $n=4$ cells). Thus, during somatic current injection, $V_{\text {soma }}$ was $\sim 5 \mathrm{mV}$ more depolarized than $V_{\text {syn }}$. Thus, in the main experiments, we depolarized $V_{\text {soma }}$ to $-50 \mathrm{mV}$ to achieve an estimated $V_{\text {syn }}$ of $-55 \mathrm{mV}$.

Juxtacellular (loose-seal) recordings in PV cells were made using $\mathrm{K}$ gluconate internal. Spikes were detected in voltage-clamp mode with $V_{\text {hold }}$ continuously adjusted to maintain a $0 \mathrm{pA}$ holding current. Spike probability was calculated over 10 sweeps for each L4 stimulus intensity.

Spontaneous miniature IPSCs (mIPSCs) were recorded in voltage clamp at $V_{\text {hold }}=0 \mathrm{mV}$, and isolated using $50 \mu \mathrm{M} \mathrm{d}-\mathrm{AP} 5,10 \mu \mathrm{M}$ NBQX, and $100 \mu \mathrm{M}$ saclofen, and $0.1 \mu \mathrm{M}$ tetrodotoxin (TTX) in the bath. Rseries compensation was not used for mIPSC recordings. Analysis was performed by semiautomatic template matching in Axograph X (Axograph Scientific). The detection threshold was 5 pA. A minimum of 300 events was analyzed per cell. mIPSC analysis was performed blind to experimental condition.

L4 optogenetic stimulation. Scnn1a-Cre mice were injected at P2-P3 with AAV2.9-CAGGS-Flex-ChR2-tdTom-WPRE-SV40 virus into S1 (catalog \#V1345, Penn Vector Core, University of Pennsylvania, Philadelphia, PA). Scnn1a-Cre mice express Cre in L4 excitatory cells (Adesnik and Scanziani, 2010; Madisen et al., 2010), and we verified L4 expression using AAV2.9-CAGGS-flex-tdTomato viral reporter (catalog 
\#V1682, Penn Vector Core; data not shown). Slices were prepared at P18-P22. The D column was readily identifiable by L4 fluorescence, which revealed the barrel pattern. A $443 \mathrm{~nm}$ laser $(40 \mathrm{~mW}$; catalog \#DL445-040, CrystaLaser) was connected via optic fiber to the microscope epifluorescence arm and projected through a $4 \times$ objective to form a 238- $\mu \mathrm{m}$-diameter spot. This was centered over the D barrel in L4. Laser power at the slice was calibrated using a power meter (catalog \#1916-R, Newport). We patched L2/3 PYR cells in the D column, and synaptic responses were measured in voltage clamp (as above, except that Rseries was not compensated). Two millisecond light pulses were applied at a $10 \mathrm{~s}$ interstimulus interval to activate L4 neurons and elicit synaptic responses in L2/3 PYR cells in the D column. For optogenetic inputoutput curves, $\mathrm{E} \theta$ was defined as the minimal laser power that evoked an EPSC in at least 5 of 10 consecutive sweeps and was determined individually for each PYR cell. Other experimental parameters were identical to the L4 electrical stimulation experiments.

To ensure sufficient ChR2 expression level in each slice, we required that tdTomato fluorescence in L4 surpass a minimum brightness (200 intensity units), measured in a $350-\mu \mathrm{m}$-diameter circular region centered on the L4 D barrel, using identical excitation power and camera settings each day. We also quantitatively measured functional ChR2 expression level in L4 using the "photo-local field potential" (LFP; Shao et al., 2013). For this measure, a $1.8-2.2 \mathrm{M} \Omega$ field potential pipette was placed in the center of the D barrel in L4 at the end of each slice recording, and TTX $(1 \mu \mathrm{M})$ and kynurenic acid $(2 \mathrm{mM})$ were added to the bath. LFP evoked by $\mathrm{L} 4$ photostimulation at $1.6 \times \mathrm{E} \theta$ was measured, which reflects bulk photocurrent in the L4 neuron population. Photo-LFP magnitude correlated with tdTomato fluorescence (data not shown). To ensure an equivalent magnitude of presynaptic stimulation between sham and deprived (Dep) groups, we restricted analysis to slices with L4 photoLFP magnitude of $>0.6$ and $<0.25 \mathrm{mV}$. Overall, 34 of 49 slices from 18 of 24 mice passed brightness and photo-LFP criteria, and were used for recordings.

$P V-P Y R$ cell pairs. To study unitary synaptic connections, we made dual whole-cell recordings from cocolumnar PV and PYR neurons $(<60$ $\mu \mathrm{m}$ apart). The PV cell was recorded in current clamp using K gluconate internal, and the PYR cell was recorded in voltage clamp using Cs gluconate internal. A five-spike train was evoked in the PV cell using current pulses ( $2 \mathrm{~ms}, 1-2 \mathrm{nA}, 50 \mathrm{~ms}$ interval). Unitary IPSCs (uIPSCs) were recorded in the PYR cell at $0 \mathrm{mV}$. Approximately 30 sweeps were collected. uIPSC amplitude was calculated in a $1.8 \mathrm{~ms}$ window centered on the peak. IPSCs were scored as outward currents $>1$ SD above spontaneous $V_{\mathrm{m}}$, initiating within $3.6 \mathrm{~ms}$ of a presynaptic spike. Two cells were considered to be connected if the probability of observing an IPSC was significantly greater after the first PV spike than during spontaneous activity before the spike (assessed over 30 sweeps, $\alpha=0.05$, binomial test). Paired-pulse ratio was defined as second uIPSC/first uIPSC amplitude. The coefficient of variation $(\mathrm{CV})$ was calculated from the variance of the first uIPSC - the variance of a spontaneous epoch. uIPSC decay time constant $(\tau)$ was calculated from a single exponential fit.

$P V$ intrinsic excitability. PV cells were recorded in whole-cell currentclamp mode. $V_{\text {rest }}$ was measured immediately after break-in. Series resistance artifacts were compensated by bridge balance. Input resistance was calculated as the slope of the linear fit of steady-state $\Delta V_{\mathrm{m}}$ during $-50,0$, and $+50 \mathrm{pA}$ current steps. The membrane time constant $(\tau)$ was calculated by single exponential fit of the first $80 \mathrm{~ms}$ of the $-50 \mathrm{pA}$ current step. Rheobase was defined as the minimum current injection $(500 \mathrm{~ms})$ that elicited one or more spikes on five consecutive sweeps. The firing-current $(F-I)$ relationship was measured using increasing currents above rheobase. $F-I$ curve slope was measured from linear fit. Spike threshold was defined as the $V_{\mathrm{m}}$ at which the second derivative of $V_{\mathrm{m}}$ was $>6$ SDs above the prestimulus period. Spike latency was defined as the time to spike threshold. Spike shape was analyzed for the second to sixth spikes during each current injection, excluding the first spike, which has a systematically different threshold in L2/3 PV cells (Goldberg et al., 2008). Cells with a spike threshold of less than $-20 \mathrm{mV}$, indicative of an undercompensated bridge, were excluded from analysis.

Potassium currents in PV neurons. Voltage-sensitive potassium (Kv) currents were recorded in voltage clamp, using $\mathrm{K}$ gluconate internal.
To minimize calcium-gated $\mathrm{K}$ currents, the internal contained $5 \mathrm{~mm}$ BAPTA, and the Ringer's solution contained low $\mathrm{CaCl}_{2}$ (0.5 mM). Sweeps were collected at $2.5 \mathrm{~s}$ intervals. To measure delayed rectifier $\mathrm{K}$ currents, the bath contained the synaptic blockers $50 \mu \mathrm{M}$ d-AP5, $10 \mu \mathrm{M}$ NBQX, 100 $\mu \mathrm{M}$ saclofen, and $3 \mu \mathrm{M}$ SR 95531 hydrobromide (gabazine); the sodium channel blocker $0.1 \mu \mathrm{M}$ TTX; the M-current $\left(I_{\mathrm{M}}\right)$ blocker $10 \mu \mathrm{M}$ XE 991 dihydrochloride; the hyperpolarization-activated cation current $\left(I_{\mathrm{h}}\right)$ blocker $0.1 \mathrm{~mm}$ ZD2788; and 0.1\% bovine serum albumin. After a prepulse to $-70 \mathrm{mV}$, we applied $300 \mathrm{~ms}$ voltage steps every $10 \mathrm{mV}$ ( -70 to $-10 \mathrm{mV})$ and every $5 \mathrm{mV}(-100$ to $-80 \mathrm{mV})$. Leak currents were measured from the second series, extrapolated to the first series, and subtracted. Delayed rectifier currents were identified as noninactivating outward currents that activate at approximately -40 to $-50 \mathrm{mV}$ (Kv1 family) or -20 to $-30 \mathrm{mV}$ (Kv2 family). Current amplitude was measured in the last $100 \mathrm{~ms}$ of the $300 \mathrm{~ms}$ pulse. Inactivating (A-type) currents are also present in these recordings but inactivate in $<50 \mathrm{~ms}$, and were ignored in analysis (Coetzee et al., 1999). To separate Kv1.1 from other delayed rectifier currents, dendrotoxin (DTX)-K (100 nM) was washed in, and DTX-insensitive currents were subtracted from the baseline current.

To measure inactivating A-type current $\left(I_{\mathrm{A}}\right)$, we used a combination of pharmacology and inactivation properties. The bath contained the synaptic blockers $50 \mu \mathrm{M}$ d-AP5, $10 \mu \mathrm{M}$ NBQX, $100 \mu \mathrm{M}$ saclofen, $3 \mu \mathrm{M}$ SR 95531 hydrobromide (gabazine); $0.1 \mu \mathrm{M}$ TTX; and $20 \mathrm{~mm}$ TEA to block most delayed rectifier current and $I_{\mathrm{M}}$. A $200 \mathrm{~ms}$ prepulse to $-70 \mathrm{mV}$ was applied, and then $V_{\mathrm{m}}$ was stepped to $0 \mathrm{mV}$ for $300 \mathrm{~ms}$. In interleaved sweeps, the prepulse was changed to $-40 \mathrm{mV}$, which inactivates $I_{\mathrm{A}}$. We isolated $I_{\mathrm{A}}$ during the $0 \mathrm{mV}$ step by subtracting sweeps with the $-40 \mathrm{mV}$ prepulse from sweeps with the $-70 \mathrm{mV}$ prepulse. Cells were held at -100 $\mathrm{mV}$ for $2.5 \mathrm{~s}$ between sweeps to allow recovery from inactivation. Current magnitude was quantified as integrated current from 1 to $26 \mathrm{~ms}$ after onset of the $0 \mathrm{mV}$ step. A small amount of noninactivating current was also observed after subtraction, and likely reflects $I_{\mathrm{h}}$, which was not blocked in these experiments. We only analyzed the $I_{\mathrm{A}}$ component. Because $I_{\mathrm{A}}$ amplitude correlated with Rseries, cells were only included if residual Rseries was 5.5-10.5 $\mathrm{M} \Omega$, which allowed precise matching of Rseries between sham and deprived cell populations ( $7.6 \pm 0.3$ and $7.5 \pm$ $0.3 \mathrm{M} \Omega$, respectively; $n=16$ cells/group).

Drugs. Drugs were from Tocris Bioscience, except TTX and dendrotoxin-k, which were both from Alomone Labs.

Parallel conductance model of PYR synaptic potentials. We used a standard parallel conductance model (Wehr and Zador, 2003) to predict synaptic potentials that would be generated in L2/3 PYR cells from recorded L4-evoked synaptic conductances. The model simulated synaptically evoked changes in $V_{\mathrm{m}}\left(\Delta V_{\mathrm{m}}\right)$ resulting from L4-evoked excitatory conductance (Gex) and inhibitory conductance (Gin) waveforms, recorded at $1.4 \times \mathrm{E} \theta$ in a single PYR neuron. Gex and Gin waveforms were constrained to be non-negative and were smoothed (Savitzky-Golay, 1 ms window). $\Delta V_{\mathrm{m}}$ was predicted using the parallel conductance equation:

$$
\mathrm{C}(\mathrm{dV} / \mathrm{dt})=\mathrm{G}_{\mathrm{ex}}\left(\mathrm{V}_{\mathrm{m}}-\mathrm{E}_{\mathrm{ex}}\right)+\mathrm{G}_{\text {in }}\left(\mathrm{V}_{\mathrm{m}}-\mathrm{E}_{\text {in }}\right)+\mathrm{G}_{\mathrm{rest}}\left(\mathrm{V}_{\mathrm{m}}-\mathrm{E}_{\mathrm{rest}}\right),
$$

where $C$ was $240 \mathrm{pF}$, which was the average membrane capacitance measured in PYR neurons in our study. $G_{\text {rest }}$ was defined as $1 / R_{\text {input }}$, where $R_{\text {input }}$ was the average input resistance measured for deprived cells ( 94 $\mathrm{M} \Omega$ ) or sham cells $(100 \mathrm{M} \Omega)$. We simulated $\Delta V_{\mathrm{m}}$ for cells at a resting equibrium potential $\left(E_{\text {rest }}\right)=-55 \mathrm{mV}$, to estimate the effect of feedforward synaptic input on $V_{\mathrm{m}}$ as a cell approaches spike threshold. $V_{\mathrm{m}}$ was calculated by integrating Equation 1 from a starting value of $V_{\mathrm{m}}=-55$ $\mathrm{mV}$ with $0.1 \mathrm{~ms}$ time resolution, using Euler's method. This is the same method used in the study by House et al. (2011).

\section{Experimental design and statistical analysis}

D-row deprived and sham mice were littermates, and were recorded interleaved either on the same day or on alternate days. All reported deprivation effects were observed across at least three independent litters. For each measurement type, data were tested for Gaussian distribution 

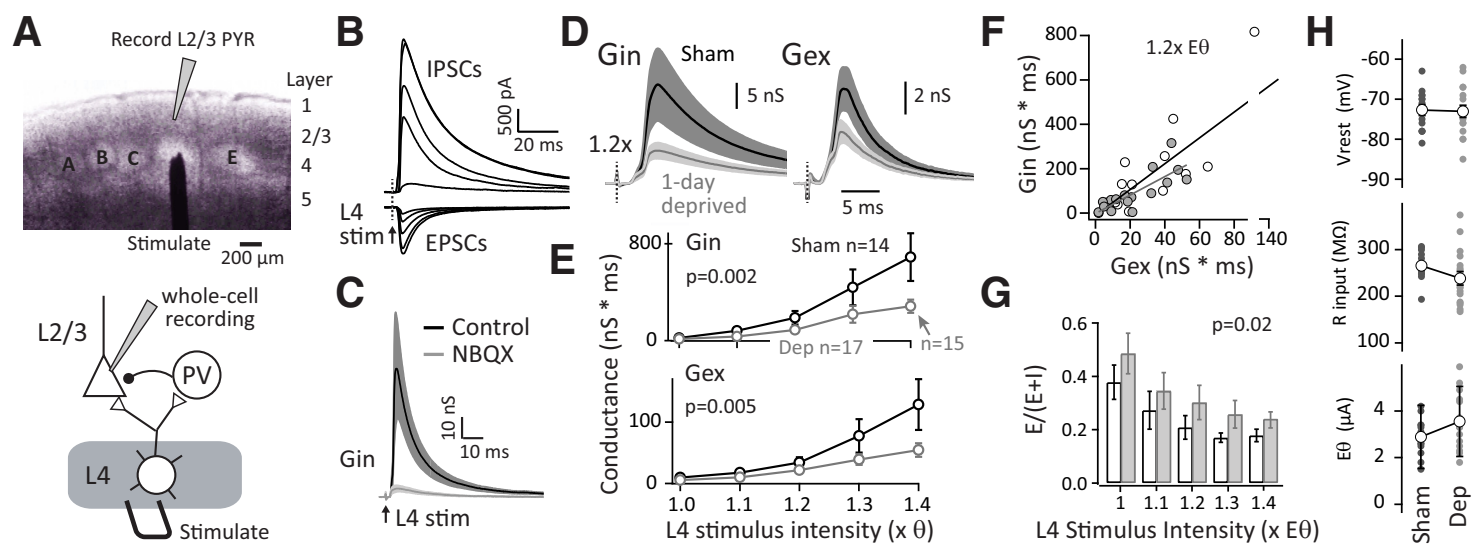

Figure 1. One day of deprivation weakens L4-evoked inhibition and increases the $E-I$ conductance ratio in L2/3 PYR cells. $\boldsymbol{A}$, Top, S1 slice with stimulating electrode in L4 of D barrel and a schematic recording electrode. Bottom, Circuit for L4 -L2/3 feedforward excitation and inhibition. $\boldsymbol{B}$, L4-evoked IPSCS and EPSCs in an example L2/3 PYR cell. Increasing currents are responses to L4

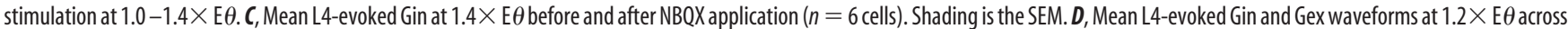
all sham $(n=14)$ and deprived $(n=17)$ cells. Shading is the SEM. $\boldsymbol{E}$, Input- output curves for integrated Gin and Gex with increasing L4 stimulation intensity. Points are the mean \pm SEM. Two deprived cells showed unclamped action currents at $1.4 \times \mathrm{E} \theta$ at $V_{\text {hold }}=0 \mathrm{mV}$, and were therefore omitted from Gin analysis at $1.4 \times \mathrm{E} \theta$. The $p$ values are for sham vs deprived factor in two-way ANOVA. $\boldsymbol{F}$, Left, Within-cell comparison of Gex vs Gin at $1.2 \times E \theta$. Each point is a cell. Lines are linear regression for sham (black) and deprived (gray). $\mathbf{G}, E-I$ conductance ratio, quantified as Gex/(Gex $+\mathrm{Gin})$, across stimulus intensities. Bars shown are the mean $\pm \mathrm{SEM}$, as in all subsequent figures. The $p$ value is sham vs deprived factor in two-way ANOVA. $\boldsymbol{H}, V_{\text {rest }}, R_{\text {input }}$ and $\boldsymbol{E} \theta$ for each cell (dots) and population mean (open circle).

before use of parametric statistics. Non-Gaussian data were evaluated using log-transformed data, nonparametric statistics, or by permutation test, as indicated in the text. Reported values are mean \pm SEM, except where indicated. All statistical tests are identified in the Results. Statistical analysis was performed in Matlab, Excel, or R.

\section{Results}

To test whether brief, $1 \mathrm{~d}$ whisker deprivation drives inhibitory circuit plasticity in L2/3 of S1, we plucked the right-side D-row whiskers in mice at P17-P20, $24 \mathrm{~h}$ before slice preparation at $\mathrm{P} 18-\mathrm{P} 21$. We cut S1 slices in the "across-row" plane that allows D whisker columns to be visually identified by transillumination (Finnerty et al., 1999; Allen et al., 2003; Fig. 1A, top). We used multiple approaches to compare cell and circuit physiology in $\mathrm{L} 2 / 3$ of the $\mathrm{D}$ column between $1 \mathrm{~d} \mathrm{D}$-row-deprived mice and age-matched, sham-deprived littermates. Most experiments used PV-Cre;tdTomato mice to enable fluorescence-guided recording from L2/3 PV neurons.

\section{L4-evoked feedforward Gex and Gin in L2/3 PYR cells}

We first studied feedforward L4-L2/3 excitation and inhibition onto PYR cells by electrically stimulating in L4 and measuring evoked EPSCs and IPSCs in L2/3 PYR cells. EPSCs and IPSCs were separated by recording at -68 and $0 \mathrm{mV}\left(E_{\mathrm{Cl}}\right.$ and $E_{\mathrm{AMPA}}$; Xue et al., 2014; Fig. 1B). NMDA receptors were blocked with D-AP5 $(50 \mu \mathrm{M})$ in all experiments. For each L2/3 PYR cell, we determined the minimal L4 stimulation intensity that evoked a reliable EPSC, termed E $\theta$. We then measured input-output curves for L4-evoked EPSCs and IPSCs at 1.0-1.4 times E $\theta$. L4 stimulation in this range did not evoke spikes from $V_{\text {rest }}$ in $\mathrm{L} 2 / 3$ PYR cells ( $n=90$ cells, 37 mice), indicating that L4 stimulation activated feedforward, rather than recurrent, L2/3 circuits.

Stimulation near E $\theta$ typically elicited an EPSC and a small IPSC. Stronger stimulation recruited larger currents, with inhibition dominating over excitation by $1.2-1.4 \times \mathrm{E} \theta$ (Fig. $1 B$ ), similar to rats (House et al., 2011; Shao et al., 2013). NBQX (10 $\mu \mathrm{M})$ blocked $85 \pm 3.6 \%$ of the L4-evoked IPSC at $1.4 \times \mathrm{E} \theta$ (Fig. $1 C$; $n=6$ cells, 5 mice), and the latency of the NBQX-sensitive IPSC was $1.05 \pm 0.26 \mathrm{~ms}$ longer than the EPSC in the same cell. These properties indicate that $\sim 85 \%$ of the measured IPSC was feed- forward, disynaptic inhibition, and that contamination by monosynaptic inhibition was modest. For analysis, EPSCs and IPSCs were converted to conductances (Gex and Gin) using standard methods (Wehr and Zador, 2003; House et al., 2011).

One day of whisker deprivation reduced input-output curves for both L4-evoked Gex and Gin in L2/3 PYR cells ( sham: $n=14$ cells, 11 mice; Dep: $n=17$ cells, 12 mice; Gex: $F_{(1,4)}=8.44, p=$ 0.0043; Gin: $F_{(1,4)}=11.2, p=0.001$; two-factor ANOVA; Fig. $1 D, E)$. At $1.2 \times \mathrm{E} \theta$, mean integrated excitation was reduced by $36 \%$, and inhibition was reduced by $53 \%$. Gex and Gin were correlated within individual cells (linear fit, $R^{2}=0.79$; Xue et al., 2014), and deprivation reduced the slope of this relationship, suggesting preferential loss of Gin (Fig. $1 F$ ). We calculated the excitation-inhibition $(E-I)$ conductance ratio as $E /(E+I)$ for each cell, and found a significant increase in $E /(E+I)$ for deprived cells across stimulus intensities $\left(F_{(1,4)}=5.88, p=0.017\right.$; Fig. $1 G) . V_{\text {rest }}, R_{\text {input }}$, and $\mathrm{E} \theta$ were not altered by deprivation, indicating that recording quality and stimulation efficacy were equal in sham versus deprived groups (Fig. 1H). Thus, $1 \mathrm{~d}$ of deprivation reduced both Gin and Gex, as previously reported for $\geq 5$ d of deprivation in rats (Shepherd et al., 2003; House et al., 2011; Shao et al., 2013), and Gin was preferentially weakened to elevate $E-I$ conductance ratio. This inhibitory plasticity is the most rapid yet reported in $\mathrm{S} 1$ cortex.

\section{Optogenetic activation of the feedforward L4-L2/3 circuit}

To confirm that deprivation affected the $\mathrm{L} 4-\mathrm{L} 2 / 3$ projection specifically, we assayed L4-L2/3 circuits optogenetically. We expressed ChR2-tdTomato in L4 excitatory cells in S1 using a Credependent viral vector in Scnn1a-Tg3-Cre mice, which express Cre in L4 excitatory cells (Adesnik and Scanziani, 2010; Madisen et al., 2010; Fig. 2A). D-row whiskers were deprived or sham deprived at P17-P21, and slices were made $24 \mathrm{~h}$ later. We activated L4 neurons using a calibrated blue laser spot centered in the $\mathrm{D}$ barrel in L4 and recorded postsynaptic currents from a L2/3 PYR cell in the D column in voltage clamp (Fig. $2 B$ ). We determined $\mathrm{E} \theta$ as the minimal laser intensity that evoked a reliable EPSC in the L2/3 PYR cell, and measured input-output curves for EPSCs and IPSCs at 1.0-2.0 $\times \mathrm{E} \theta$. Near E $\theta$, photostimulation 

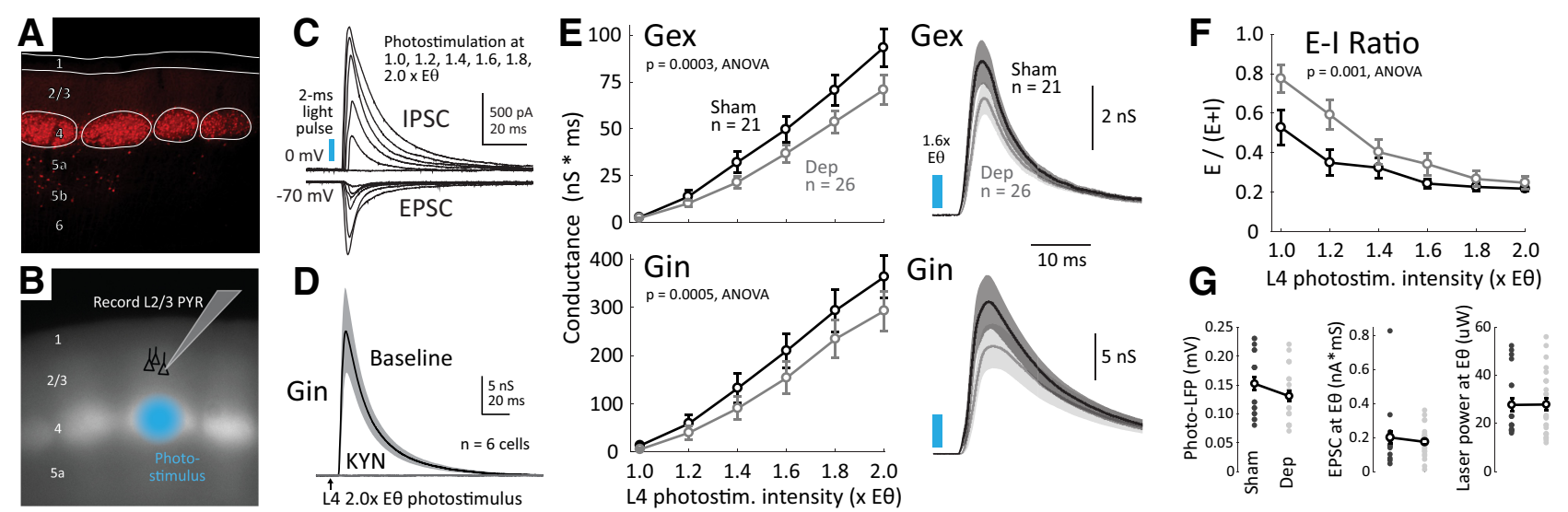

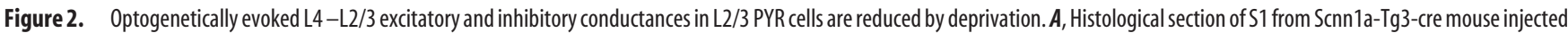
with AAV2.9-CAGGS-flex-tdTom. tdTomato signal (red) is restricted to $L 4$, except for a few $L 5$ neurons. White outlines are $L 4$ barrels. $B$, Live fluorescence image during a physiology experiment of slice from a mouse injected with flex-ChR2-tdTom virus. Bright signal is ChR2-tdTomato in L4 soma and axons. Schematic shows photostimulation spot in L4 and whole-cell recording in L2/3 of the D column. C, Photo-evoked IPSCS and EPSCs in an example L2/3 PYR cell. Increasing currents are responses to L4 optogenetic stimulation at 1.0 $2.0 \times$ E $\theta$. D, Mean IPSC ( $n=6$ cells) is completely blocked by bath application of kynurenic acid. $E$, Left, Mean input- output curves for L4-evoked Gex and Gin with increasing photostimulus intensity. Points are the mean \pm SEM. The $p$ values are for sham vs deprived factor in two-factor ANOVA on log-transformed data. Right, Mean conductance waveforms at $1.6 \times \mathrm{E} \theta$. $\boldsymbol{F}, E-I$ conductance ratio across stimulation intensities, quantified as $\mathrm{Gex} /(\mathrm{Gex}+\mathrm{Gin})$. G, Sham and deprived groups did not differ in photo-LFP amplitude (measured in $L 4$ at $1.6 \times E \theta$ ), EPSC at $E \theta$, or laser power at $E \theta$. Each dot is a cell, open circles are the population mean \pm SEM.

evoked small EPSCs and IPSCs. Increasing photostimulus intensity recruited larger EPSCs and IPSCs, with IPSCs increasing preferentially to dominate the response (Fig. 2C). This result is similar to L4 electrical stimulation (Fig. 1) and to optogenetic activation of $\mathrm{L} 2 / 3$ recurrent networks in slices and in vivo (Mateo et al., 2011; Shao et al., 2013). Evoked currents were somewhat smaller and slower than with electrical stimulation. Evoked IPSCs were completely blocked by the glutamate receptor antagonist kynurenic acid ( $2 \mathrm{~mm}$ ), with no contamination by monosynaptic inhibition (Fig. 2D).

One day of deprivation reduced input-output curves for both photo-evoked Gex and Gin $(n=21$ sham cells, $n=26$ deprived cells; Gex: $F_{(1,5)}=13.4, p=0.0003$; Gin: $F_{(1,5)}=12.3, p=$ 0.00054; two-factor ANOVA on log-transformed data; Fig. $2 E$ ). Deprivation reduced Gex and Gin waveforms, but kinetics were unaffected. Deprivation also increased $E-I$ ratio, calculated as $E /(E+I)$ within each cell $\left(F_{(1,5)}=11.1, p=0.00096\right.$; Fig. $\left.2 F\right)$. This was particularly apparent at low photostimulus intensities, representing initial recruitment of the feedforward circuit. There was no difference between sham and deprived groups in photoLFP magnitude in L4, which reflects bulk ChR2 photocurrent (see Materials and Methods), size of the EPSC at E $\theta$ or laser power at $\mathrm{E} \theta$ ( $t$ test, $p=0.16, p=0.47,0.96$ ). These results indicate similar presynaptic L4 activation and initial recruitment of L4-L2/3 excitation in the two conditions (Fig. 2G). Thus, deprivation weakens feedforward L4-L2/3 excitation and inhibition, measured selectively by L4 optogenetic stimulation.

Gex and Gin magnitude, kinetics, and input-output curve shape differed moderately between electrical and ChR2 stimulation experiments (Figs. 1D-G, 2E,F). This likely reflects differences in cellular specificity, spike synchrony, and spatial focus of the two methods, and the use of Rseries compensation in the electrical but not the optogenetics experiment. Deprivation produced nearly identical physiological effects despite these methodological differences.

\section{L4-evoked spiking in L2/3 PV cells}

To identify the circuit mechanism underlying weakened L4-L2/3 feedforward inhibition, we studied L2/3 PV interneurons, which classically mediate this inhibition (Helmstaedter et al., 2008; House et al., 2011; Xue et al., 2014). We first tested whether deprivation alters L4-evoked spiking of L2/3 PV cells. We recorded in the $\mathrm{D}$ column of PV-Cre;tdTomato mice (Fig. $3 A, B$ ). In each column, we determined the mean E $\theta$ in two PYR cells and then recorded L4-evoked spikes in L2/3 PV cells in cell-attached mode in response to $\mathrm{L} 4$ electrical stimulation at multiples of $\mathrm{E} \theta$. In sham mice, a small number of PV spikes occurred at $<1.4 \times$ $\mathrm{E} \theta$, and most PV spiking occurred from 1.8 to $2.2 \times \mathrm{E} \theta(n=28$ PV cells, 7 mice; Fig. $3 C$ ). L2/3 PYR cells recorded in cell-attached mode did not spike at all in this stimulus range $(n=24$ cells, 6 mice). One day of D-row deprivation strongly reduced spike probability in PV cells ( $n=19$ cells, 6 mice, Fig. $3 C)$ as well as the fraction of PV cells spiking to each stimulus (Fig. 3D). Deprivation reduced the mean spike probability by $63 \%$, from $0.49 \pm$ 0.07 spikes/stimulus in sham cells (combined across $1.8-2.2 \times$ $\mathrm{E} \theta)$ to $0.18 \pm 0.05$ in deprived cells. This decrease was significant ( $p=0.034$, permutation test on summed spikes across the inputoutput curve). Deprivation did not alter the latency of evoked spikes (at 2.2 $\times$ : sham, $5.71 \pm 0.52 \mathrm{~ms}$; deprived, $5.23 \pm 0.42 \mathrm{~ms}$ ). The rapid loss of feedforward inhibition in L2/3 PYR cells is therefore mediated, at least in part, by reduced L4-evoked spiking in PV neurons, as occurs with brief deprivation in visual cortex (Kuhlman et al., 2013).

\section{Synaptic input to L2/3 PV cells}

Prolonged (6-12 d) whisker deprivation in rat S1 and brief $(1 \mathrm{~d})$ visual deprivation in mouse V1 both reduce spiking of L2/3 PV cells by weakening L4 excitatory synaptic drive onto PV cells (House et al., 2011; Kuhlman et al., 2013; Sun et al., 2016). To test whether the same mechanism is engaged during $1 \mathrm{~d}$ whisker deprivation in mice, we made whole-cell voltage-clamp recordings from L2/3 PV cells in PV-Cre;tdTomato mice. We measured input-output curves for L4 electrical stimulation-evoked Gex and Gin in PV cells at $1.0-2.2 \times \mathrm{E} \theta$, where $\mathrm{E} \theta$ was determined as the mean E $\theta$ for two cocolumnar PYR cells. Surprisingly, L4-evoked Gex was identical between sham and deprived cells (sham: $n=16$ cells, 10 mice; deprived: $n=12$ cells, 8 mice; $F_{(1,6)}=1.5, p=0.22$, two-factor ANOVA), as was Gin (also $F_{(1,6)}=1.5, p=0.22$; 

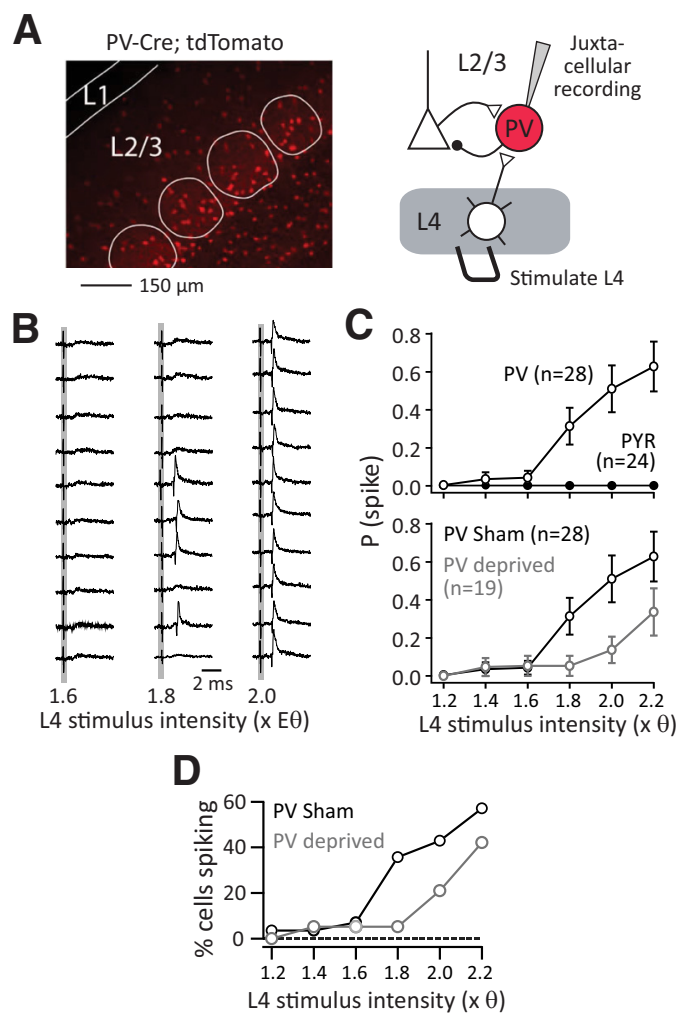

Figure 3. Deprivation reduces $L 4$-evoked spiking of $L 2 / 3 P V$ cells. $A$, Left, Fluorescent $P V$ cells in an S1 slice from PV-Cre/TdTomato mouse. White, L4 barrels. Right, Schematic of cellattached recording of $L 4$-evoked spikes in L2/3 PV neurons. $\boldsymbol{B}$, Example spiking data from one PV neuron. Ten sweeps at three stimulation intensities are shown. Gray, Stimulus artifact. $\boldsymbol{C}$, Mean spike probability for PV and PYR neurons from sham mice (top), and for PV neurons in sham vs deprived mice (bottom). D, Fraction of PV cells spiking in sham vs deprived mice.

Fig. $4 A, B) . V_{\text {rest }}, R_{\text {input }}$, and $\mathrm{E} \theta$ were unchanged between sham and deprived PV cells (Fig. 4C), as were Rseries and whole-cell capacitance (data not shown). We also performed separate recordings from PV cells in current clamp, and measured inputoutput curves for L4-evoked PSPs. Baseline $V_{\mathrm{m}}$ was held at -68 $\mathrm{mV}$ in this experiment, which is equal to mean $V_{\text {rest }}$ for $\mathrm{L} 2 / 3 \mathrm{PV}$ cells (Fig. 4C). The L4-evoked PSP peak was identical between sham and deprived mice ( ham: $n=6$ cells, 3 mice; deprived: $n=$ 6 cells, 4 mice; $F_{(1,6)}=1.53, p=0.22$, ANOVA; Fig. $\left.4 D\right)$. Thus, multiple measures of synaptic input to PV cells revealed apparently normal synaptic input after $1 \mathrm{~d}$ of deprivation, suggesting that PV spiking is reduced by a different mechanism than that for prolonged whisker deprivation.

\section{L2/3 PV inhibition onto L2/3 PYR cells}

Weakening of feedforward inhibition in L2/3 PYR cells could also reflect weakening or loss of inhibitory synapses on L2/3 PYR cells, as occurs after long-duration activity manipulations (Xue et al., 2014). To test this, we first examined whether $1 \mathrm{~d}$ of deprivation weakens uIPSCs from L2/3 PV to PYR cells. We made dual whole-cell recordings from nearby L2/3 PV and PYR cells in D whisker columns (Fig. 5A). We recorded uIPSCs in the PYR cell (in voltage clamp with $\mathrm{Cs}$ internal at $0 \mathrm{mV} V_{\text {hold }}$ ) in response to a five-spike train in the PV cell (Fig. 5B). uIPSC amplitude was not decreased in deprived slices. Indeed, deprived pairs showed a nonsignificant trend for a larger first UIPSC (uIPSC1; sham: $n=$ 11 pairs, 9 mice, $183 \pm 87$ pA; deprived: $n=10$ pairs, 8 mice; amplitude, $280 \pm 84 \mathrm{pA} ; t_{(19)}=-0.80, p=0.43$, $t$ test; Fig. $5 B$ ). This was not due to variations in intersoma distance (sham,
$24.2 \pm 5.1 \mu \mathrm{m}$; deprived, $35.4 \pm 4.6 \mu \mathrm{m}, p=$ n.s.; $t_{(18)}=-1.58$, $p=0.13, t$ test). Deprivation did not alter the paired-pulse ratio (uIPSC2/uIPSC1), the failure rate for UIPSC1, the CV for uIPSC1, or connection probability (Fig. 5C). Deprivation did not alter short-term depression during the five-spike train (Fig. 5D). Deprivation did speed the decay kinetics of UIPSC1 (decay $\tau$ : sham, $12.8 \pm 1.9 \mathrm{~ms}$; deprived, $7.8 \pm 0.5 \mathrm{~ms} ; t_{(18)}=2.54, p=$ $0.02, t$ test), which could suggest changes in GABA receptor subunit composition or other modification of gating properties with deprivation (Fritschy and Panzanelli, 2014; Fig. 5E).

To screen more broadly for the weakening of inhibitory synapses on PYR cells, we analyzed spontaneous mIPSCs in L2/3 PYR cells in the D column (Fig. 5F). Deprivation did not weaken mIPSCs. Instead, we observed a nonsignificant trend toward larger mIPSCs (sham: $21.5 \pm 0.75 \mathrm{pA}$ amplitude, $n=16$ cells, 3 mice; deprived: $23.7 \pm 0.1 \mathrm{pA}, n=14$ cells, 3 mice; $t_{(28)}=-1.69$, $p=0.10, t$ test), and no change in interevent interval (IEI: sham, $77.0 \pm 5.0 \mathrm{~ms}$; deprived, $\left.73.6 \pm 7.0 \mathrm{~ms} ; t_{(28)}=0.40, p=0.69\right)$. Thus, we found no evidence for weakened inhibitory synapses onto L2/3 PYR cells after $1 \mathrm{~d}$ of deprivation, either from mIPSCs or PV > PYR uIPSCs. If anything, small trends were apparent toward increased uIPSCs and increased mIPSC amplitude, reminiscent of the strengthening of PV $>$ PYR uIPSCs after $\geq 5 \mathrm{~d}$ of deprivation in rats (House et al., 2011).

\section{Reduced intrinsic excitability of L2/3 PVs cells}

Could the reduction in L4-evoked PV spiking reflect the reduced intrinsic excitability of PV cells? PV intrinsic excitability is plastic in response to extensive pharmacological or genetic blockade of network activity (Miller et al., 2011; Dehorter et al., 2015) and to $30 \mathrm{~d}$ whisker deprivation (Sun, 2009). To test whether $1 \mathrm{~d}$ of deprivation alters intrinsic excitability, we made current-clamp recordings from $\mathrm{L} 2 / 3 \mathrm{PV}$ cells in the presence of synaptic blockers (in $\mu \mathrm{M}$ : $50 \mathrm{D}-\mathrm{AP} 5,10 \mathrm{NBQX}$, and 3 gabazine) and injected $500 \mathrm{~ms}$ current steps to evoke spikes and measure $F-I$ curves (Fig. $6 A$ ). Deprivation reduced PV spiking, causing a $22 \%$ reduction in the slope of $F-I$ curves ( $n=24$ sham cells, $n=23$ deprived cells; $F_{(1,6)}=12.6, p=0.0004$, two-factor ANOVA). This corresponded to a reduction from $31.2 \pm 2.1$ to $25.0 \pm 2.1$ spikes at 80 pA above rheobase (Fig. 6B). This was associated with a depolarized spike threshold (sham: $-35.3 \pm 0.05 \mathrm{mV}, n=7626$ spikes; Dep: $-32.3 \pm 0.05 \mathrm{mV}, n=6123$ spikes, $p=1 \mathrm{e}-5, t$ test, calculated for all spikes at $0-40 \mathrm{pA}$ above rheobase; Fig. $6 C$ ). In contrast, $V_{\text {rest }}$, membrane time constant, input resistance, and rheobase were unchanged (Fig. 6D). Analysis of spike shape showed that deprivation increased the mean spike threshold by $2.6 \mathrm{mV}$ and decreased spike height (peak threshold, $54.2 \pm 1.3 \mathrm{vs}$ $50.0 \pm 1.6 \mathrm{mV} ; t_{(44)}=2.08, p=0.04, t$ test $)$, but did not alter peak $V_{\mathrm{m}}$, spike width, or afterhyperpolarization $(p=0.34, p=0.13$, $p=0.49$; Fig. $6 E, F)$.

Many L2/3 PV cells exhibit a delayed spiking phenotype characterized by a long first-spike latency at rheobase (Gibson et al., 1999; Goldberg et al., 2008), which we also observed (Fig. 6G). Prolonged upmodulation or downmodulation of network activity can alter first-spike latency due to the plasticity of voltageactivated potassium currents (Goldberg et al., 2008; Dehorter et al., 2015). We found that $1 \mathrm{~d}$ of deprivation increased first-spike latency by $\sim 20 \mathrm{~ms}\left(F_{(1,6)}=9.6, p=0.0021\right.$, two-factor ANOVA; Fig. $6 H, I)$, which lowered spike probability in early time windows after current injection onset $\left(F_{(1,9)}=11.2, p=0.0009\right.$; Fig. $6 J)$. Thus, deprivation substantially decreased intrinsic the excitability of L2/3 PV cells by increasing spike threshold, reducing 

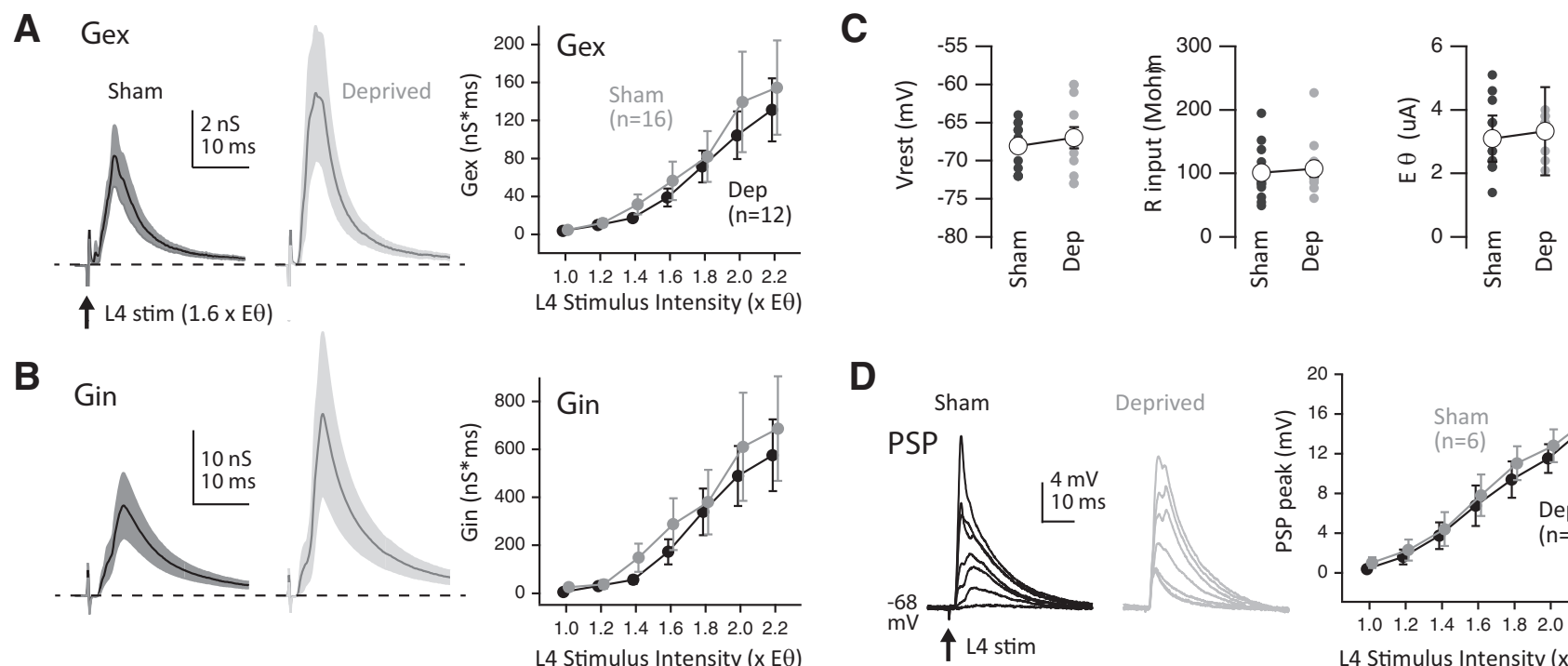

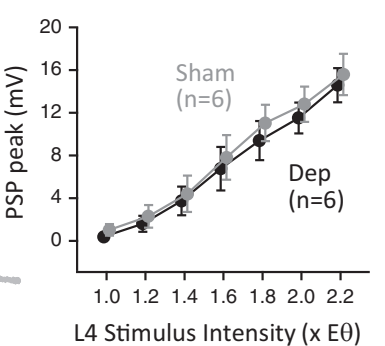

Figure 4. L4-evoked synaptic input to L2/3 PV cells remains normal during deprivation. A, Mean L4-evoked excitatory synaptic conductance in sham and deprived mice. Left, Mean Gex waveform at $1.6 \times$ stimulation intensity. Right, Mean integrated Gex across stimulus intensities. Shaded regions and bars are the SEM. B, Mean L4-evoked inhibitory synaptic conductance. Conventions are as in $\boldsymbol{A}$. Curves are displaced slightly along the $x$-axis for readability. $C, V_{\text {rest }}, R_{\text {input' }}$ and $E \theta$ for L2/3 PV cells in the experiments in $\boldsymbol{A}$ and $\boldsymbol{B}$. D, Left, L4-evoked PSPs in two example PV cells at 1.0, 1.2, .., $2.2 \times \mathrm{E} \theta$. Right, Mean PSP peak above $-68 \mathrm{mV}$ baseline $V_{\mathrm{m}^{\prime}}$ for all PV cells in sham vs deprived mice. One cell in each group spiked beginning at $1.8 \times \mathrm{E} \theta$.

spike probability, and delaying the time to first spike after current injection.

\section{Deprivation upregulates voltage-activated Kv currents in L2/3 PV cells}

To investigate the mechanisms for reduced intrinsic excitability of L2/3 PV cells, we focused on two voltage-activated potassium currents that are known to regulate spike threshold in PV cellsthe low threshold, which sustained delayed-rectifier potassium current (mediated by Kvl channels), and the transient $I_{\mathrm{A}}$ current (mediated by Kv1.4 and Kv4 channels; Gutman et al., 2005; Goldberg et al., 2008; Sun, 2009; Dehorter et al., 2015). Kv1 channels modulate spike threshold and first-spike latency in PV cells (Goldberg et al., 2008; Dehorter et al., 2015), and their expression is bidirectionally regulated by large-scale manipulations of neural activity (Dehorter et al., 2015). $I_{\mathrm{A}}$ also regulates PV spike threshold and may be altered by sustained whisker deprivation (Sun, 2009). Whether either is altered rapidly by brief sensory manipulations is unknown.

To measure delayed rectifier current, we used a whole-cell voltage-clamp protocol that stepped $V_{\text {hold }}$ from -70 to $-10 \mathrm{mV}$ in $10 \mathrm{mV}$ steps (Fig. $7 \mathrm{~A}, B$ ). The bath contained synaptic blockers (D-AP5, NBQX, saclofen, and gabazine), the sodium channel blocker TTX $(0.1 \mu \mathrm{M})$, the $I_{\mathrm{M}}$ blocker XE $991(10 \mu \mathrm{M})$, the $I_{\mathrm{h}}$ blocker ZD2788 (0.1 mM), and low $\mathrm{Ca}^{2+}(0.5 \mathrm{~mm})$ to reduce $\mathrm{Ca}$-activated $\mathrm{K}$ currents. The $\mathrm{K}$ gluconate internal contained BAPTA to further reduce Ca-activated $\mathrm{K}$ currents. These conditions isolate delayed rectifier currents mediated by Kv1 and Kv2 families (which can be separated by activation threshold) and A-type currents that can be identified by their rapid inactivation. To further separate Kv1.1 from other currents, midway through each recording we washed in the blocker DTX-K at $0.1 \mu \mathrm{M}$, a Kv1.1-selective concentration (Robertson et al., 1996; Wang et al., 1999; Shen et al., 2004), and measured DTX-K-insensitive (non-Kv1.1) and DTX-K-sensitive currents. We obtained complete data from 13 sham PV cells and 13 deprived PV cells. Deprivation did not alter leak current (Fig. 7C), but increased a steady-state $\mathrm{K}$ current that activated at -40 to $-50 \mathrm{mV}$ (Fig.
$7 D, E$, top row, $F_{(1,5)}=5.16, p=0.025$, two-factor ANOVA). This activation range is characteristic of Kvl family channels (Coetzee et al., 1999). Steady-state currents in the presence of DTX-K were also significantly larger in deprived cells (Fig. $7 D, E$, middle row; $\left.F_{(1,5)}=17.4, p=0.0001\right)$, suggesting that non-Kv1.1 channel currents were upregulated. DTX-K-sensitive currents, calculated by subtraction, were unchanged (Fig. $7 D, E$, bottom row). These data indicate that a Kv1 channel, but not a Kv1.1 channel, is upregulated by $1 \mathrm{~d}$ of deprivation to reduce the nearthreshold excitability of L2/3 PV cells.

We examined $I_{\mathrm{A}}$ in separate experiments using a voltage protocol that isolates $I_{\mathrm{A}}$ based on its rapid inactivation at $-40 \mathrm{mV}$ (Guan et al., 2011; Fig. $7 F$ ). We stepped $V_{\text {hold }}$ to $0 \mathrm{mV}$, which strongly activates $I_{\mathrm{A}}$, either from a $-70 \mathrm{mV}$ prepulse, where $I_{\mathrm{A}}$ is not inactivated, or from a $200 \mathrm{~ms}-40 \mathrm{mV}$ prepulse, which inactivates $I_{\mathrm{A}}$. The bath contained synaptic blockers, TTX, $0.5 \mathrm{~mm}$ $\mathrm{Ca}^{2+}$ to reduced Ca-activated $\mathrm{K}$ currents, and $20 \mathrm{mM}$ TEA to block most delayed rectifier K currents. Under these conditions, subtraction of $-40 \mathrm{mV}$ prepulse traces from $-70 \mathrm{mV}$ prepulse traces reveals $I_{\mathrm{A}}$, which shows characteristic inactivation over $\sim 30 \mathrm{~ms}$ (Fig. $7 F$ ). Data were obtained from 16 sham and 16 deprived cells (6 mice each). $I_{\mathrm{A}}$ current magnitude was greater in Deprived PV cells than in sham PV cells (sham, $10.5 \pm 1.0 \mathrm{nA}$ * $\mathrm{ms}$; deprived, $14.2 \pm 1.1 \mathrm{nA}{ }^{\star} \mathrm{ms} ; t_{(30)}=-2.4, p=0.021, t$ test; Fig. 7G,H). Thus, both $I_{\mathrm{A}}$ and delayed rectifier currents were increased by deprivation in L2/3 PV cells, which are expected to elevate spike threshold and reduce spike probability.

\section{Functional effect of reduced inhibition on L2/3 PYR synaptic potentials}

What is the functional effect of reduced PV-mediated inhibition on overall feedforward PSPs in L2/3 PYR cells? This will depend on its coordination with the co-occurring reduction in feedforward excitation in these neurons. We first addressed this question using a standard parallel conductance model (Wehr and Zador, 2003; House et al., 2011) to predict the net PSP produced in each L2/3 PYR cell by the measured L4-evoked Gex and Gin waveforms at $1.4 \mathrm{E} \theta$ (data from Fig. 1). The model calculates the PSP 
produced by Gex and Gin waveforms at a specific baseline $V_{\mathrm{m}}$, given excitatory and inhibitory reversal potentials $(0$ and -68 $\mathrm{mV}$ ). Input resistance and cell capacitance were set to the average values obtained from current-clamp recordings (sham: 95 $\mathrm{M} \Omega, 240 \mathrm{pF}, n=12$ cells; Dep: $101 \mathrm{M} \Omega$, $240 \mathrm{pF}, n=13$ cells). The model is passive and has no free parameters. We used a baseline $V_{\mathrm{m}}$ of $-55 \mathrm{mV}$ to predict PSPs generated just below spike threshold, which may be most relevant to understanding evoked spiking in vivo.

Figure $8 A$ shows an example cell, with the predicted EPSP and IPSP generated by the measured Gex and Gin waveforms separately, and the total PSP predicted from Gex and Gin acting together. Deprived cells showed a significantly smaller predicted IPSP (from Gin alone) than sham cells $(-5.4 \pm 0.71$ and $-7.6 \pm 0.95$ $\mathrm{mV} ; n=14$ and $15 ; p=0.046$, Wilcoxon rank-sum test), and a trend toward a smaller predicted EPSP (from Gex alone; $8.8 \pm 1.6$ and $13.2 \pm 3.0 \mathrm{mV}, p=0.16)$. This represents a similar average reduction in predicted IPSP and EPSP amplitudes (29\% and 33\%, respectively; Fig. $8 B)$. Predicted EPSP/IPSP ratio, quantified as $E /(E+I)$ within each cell, was also unchanged (sham: $0.60 \pm 0.03, n=14$; Dep: $0.61 \pm 0.03, n=15 ; p=0.67$ ). This contrasts with the preferential weakening of Gin over Gex at the conductance level (Fig. 1). Modeling Gex and Gin together predicted a total PSP comprising a characteristic EPSP-IPSP sequence (Pouille and Scanziani, 2001; Gabernet et al., 2005; House et al., 2011). Strikingly, deprivation did not alter the predicted PSP peak, although the late hyperpolarization was reduced (Fig. $8 C, D$ ). This indicates that deprivation-induced changes in Gin and Gex are quantitatively coordinated to maintain the stability of peak feedforward PSPs in L2/3 PYR cells in the justsubthreshold regime.

To test the model predictions, we measured PSPs in L2/3 PYR cells in response to $\mathrm{L} 4$ stimulation at $1.4 \times \mathrm{E} \theta$, using $\mathrm{K}$ gluconate internal ( $n=12$ sham, $n=13$ deprived). Current was injected somatically to achieve an estimated baseline synaptic $V_{\mathrm{m}}$ of $-55 \mathrm{mV}$ (see Materials and Methods). While PSP amplitude was heterogeneous across cells, the mean PSP consisted of an EPSP-IPSP sequence that was very similar to the modeled PSPs (Fig. $8 E$ ). Confirming the model, deprivation did not alter PSP peak $(p=0.68$, Wilcoxon ranksum test), but tended to reduce the late hyperpolarization phase of the PSP (nonsignificant trend, $p=0.18$; Fig. $8 F$ ). PSP duration was not significantly increased (width at half-height: sham: $6.4 \pm$ $2.4 \mathrm{~ms}, n=12$; Dep: $9.6 \pm 2.3 \mathrm{~ms}, n=13$; $p=0.19$ ). Thus, deprivation-induced changes in Gin and Gex were functionally

C

$\mathbf{F}$ cell.
B
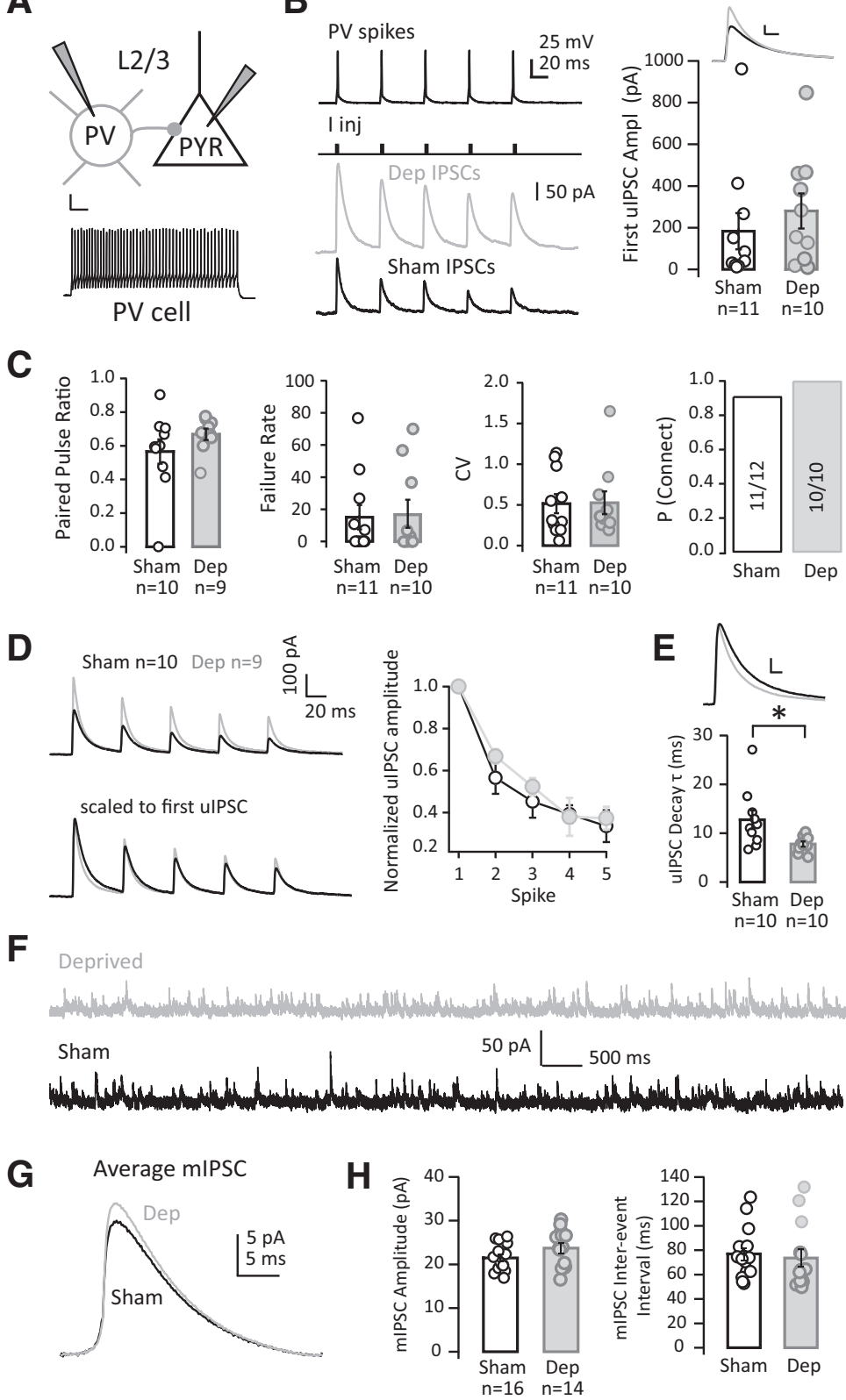

Figure 5. Unitary PV $\rightarrow$ PYR IPSCs and mIPSCs on $L 2 / 3$ PYR cells. $A$, Schematic for PV $\rightarrow$ PYR paired recordings. Bottom, Example presynaptic PV spike train. Calibration: $20 \mathrm{mV}, 50 \mathrm{~ms}$. B, Left, Presynaptic PV spike train and example ulPSCs evoked in one

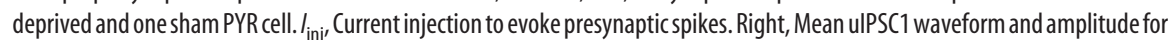
all sham and deprived pairs. Each dot is one pair. C, Paired-pulse ratio (UIPSC2/ulPSC1), ulPSC1 failure rate, uIPSC1 CV, and the probability of connected pairs. Each dot is one pair. D, Left, Population mean uIPSC train for sham and deprived pairs (top), normalized to the first ulPSC peak (bottom). Deprived pairs showed no evidence of uIPSC weakening, and a nonsignificant trend toward uIPSC strengthening, with no change in short-term plasticity during the train (right). $E$, Mean ulPSC1 across all cells and analysis of decay $\tau$. Each dot is one pair. $\boldsymbol{F}$, Example $\mathrm{mIPCS}$ recorded at $0 \mathrm{mV}$ in one sham and one deprived L2/3 PYR cell. $\boldsymbol{G}$, Mean mIPSC waveform ( $n=16$ sham, $n=14$ deprived cells). $\boldsymbol{H}$, mIPSC amplitude and IEl for sham and deprived cells. Each circle is one

balanced for L2/3 PYR cells just below spike threshold, so that L4-evoked synaptic responses remained stable after deprivation, at least for low-frequency inputs.

\section{Discussion}

Whisker deprivation weakens PV-mediated feedforward inhibition in $\mathrm{L} 2 / 3$ of $\mathrm{S} 1$ in just $24 \mathrm{~h}$, as rapidly as visual deprivation in V1 or hearing loss in A1 (Kuhlman et al., 2013; Sun et al., 2016; Resnik and Polley, 2017). Thus, rapid inhibitory circuit plasticity 

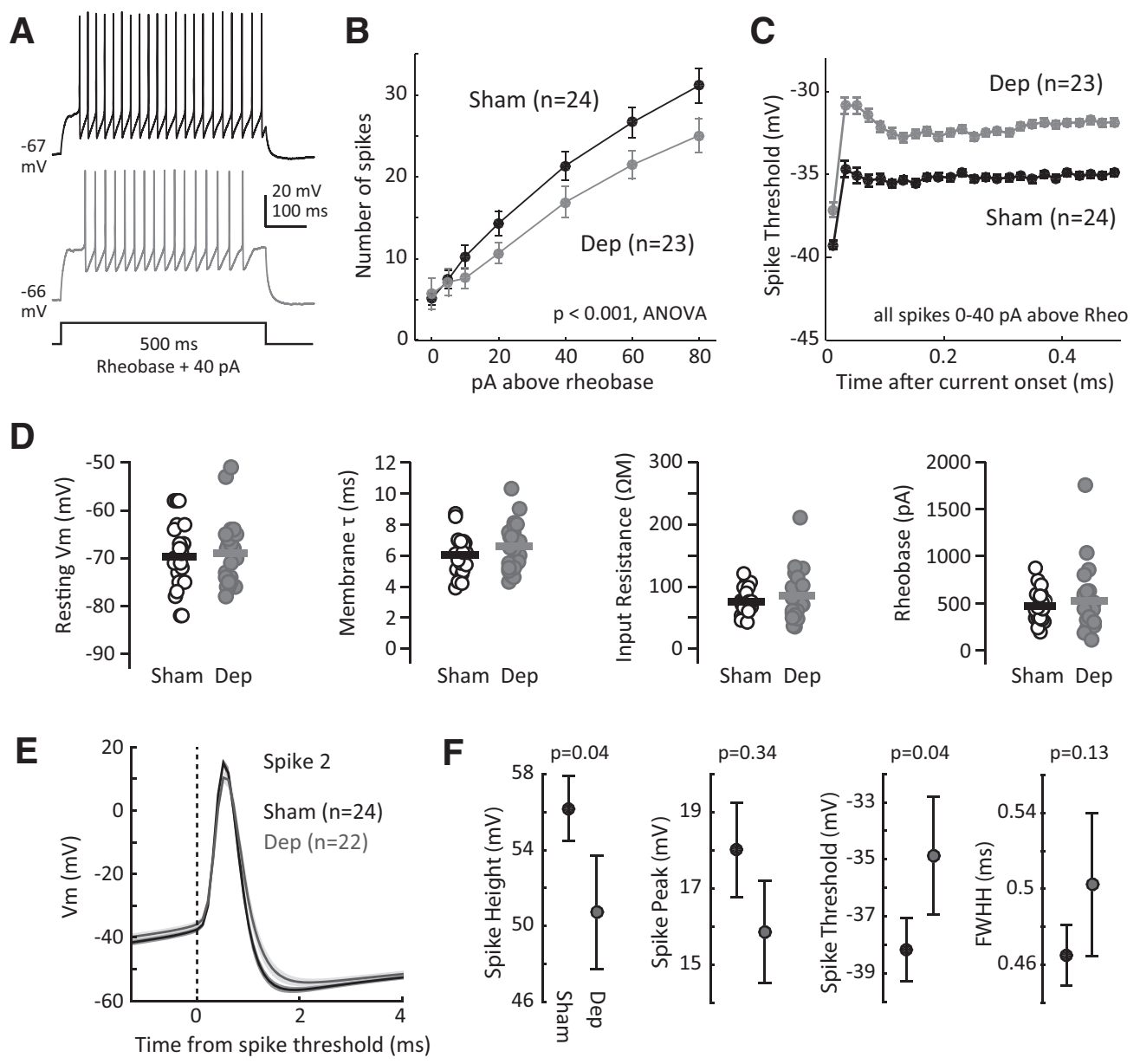

G
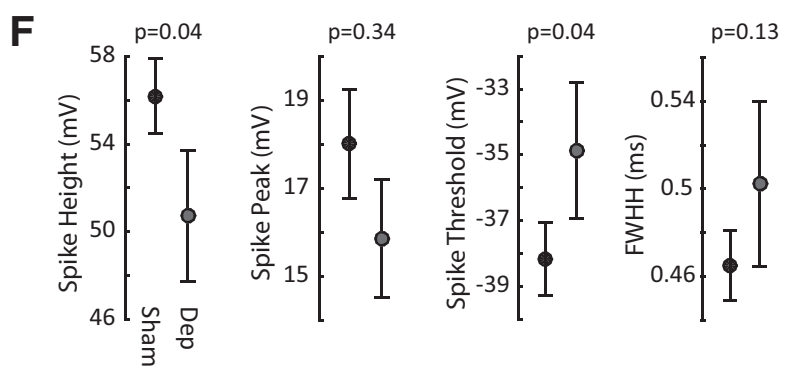

G Rheobase

Rheobase +20 pA

Rheobase +80 pA
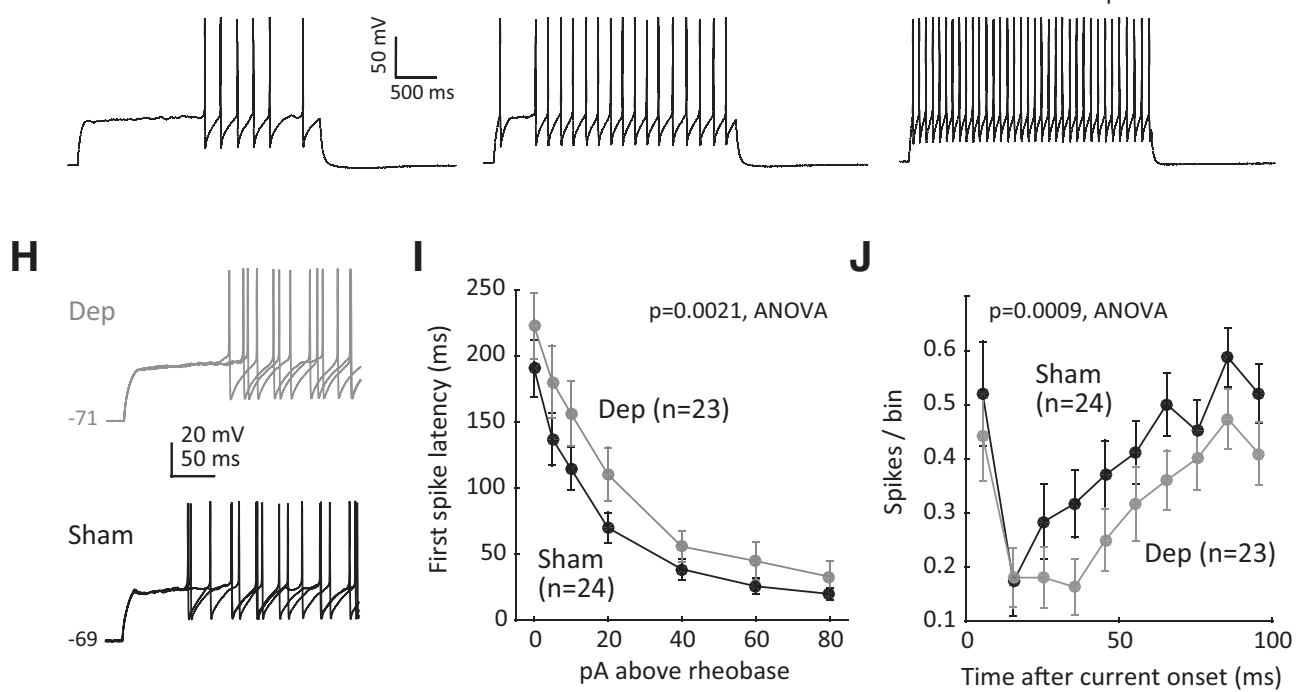

Figure 6. Deprivation causes a reduction in the intrinsic excitability of $L 2 / 3$ PVs. $A$, Spike trains for example sham (top) and deprived (bottom) $L 2 / 3$ PV cells to current injection at 40 pA above rheobase. $\boldsymbol{B}$, Mean F-I curve for spiking in sham and deprived PV cells. Symbols show the mean \pm SEM. C, Mean spike threshold, for all spikes recorded at $0-40 \mathrm{pA}$ above rheobase, in $20 \mathrm{~ms}$ time bins. Many PV cells exhibit a rapid-onset first spike with systematically lower threshold (first point, see example in $\mathbf{G}$ ). $\boldsymbol{D}$, Resting properties and rheobase for each PV cell. Bars are means. $\boldsymbol{E}$, Mean shape of second spike at $80 \mathrm{pA}$ above rheobase, across all cells. Shaded regions are \pm SEM. $F$, Quantification of spike shape for spikes at $80 \mathrm{pA}$ above rheobase. The $p$ values are from two-tailed $t$ tests. $\mathbf{G}$, Spike trains for an example PV cell showing delayed spike onset at rheobase. $\boldsymbol{H}$, Spiking of an example sham (bottom) and deprived (top) PV cell at 5 pA above rheobase, showing longer spike latency in the deprived cell. I, Mean first-spike latency in sham and deprived cells. J, Mean spike probability in $10 \mathrm{~ms}$ bins after current injection onset ( $20-80 \mathrm{pA}$ above rheobase). The $p$ values in $I$ and $J$ are for sham vs deprived factor in two-way ANOVA. 
A
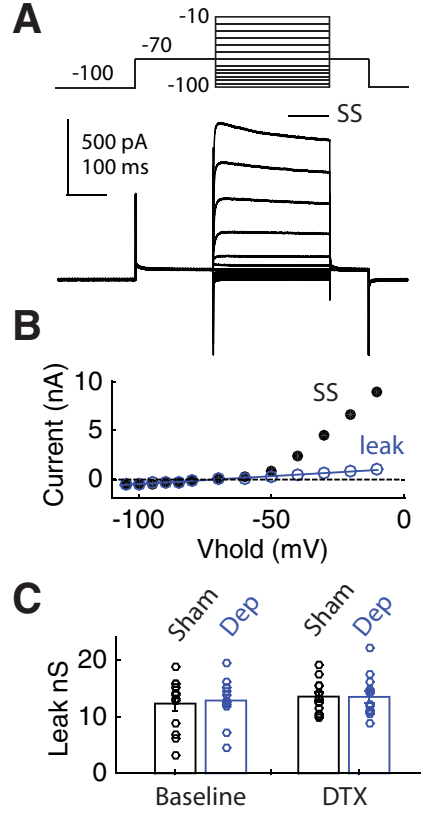

$\mathbf{F}$

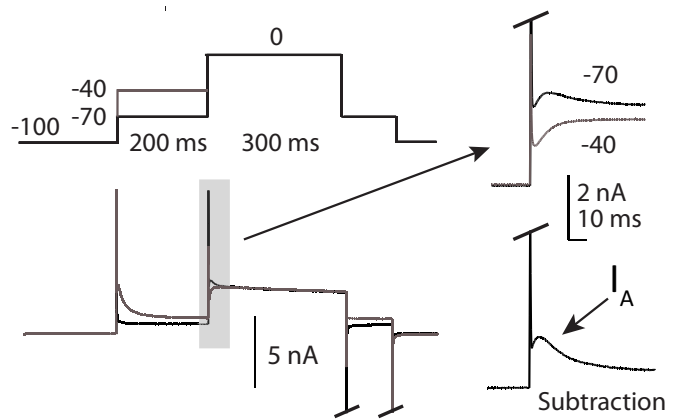

D
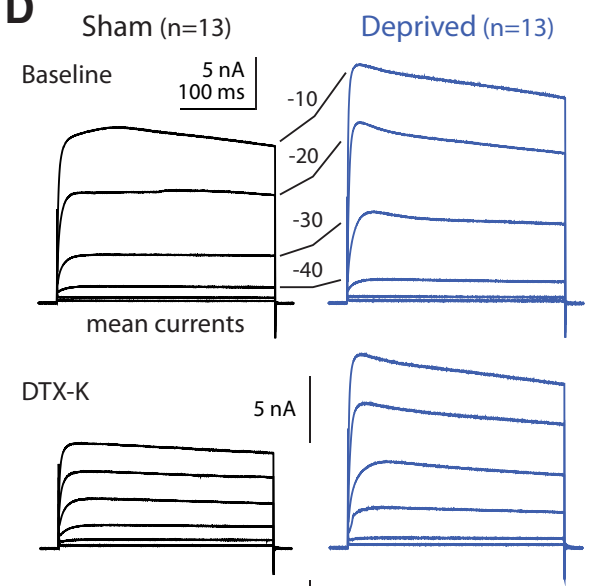

DTX-sensitive current
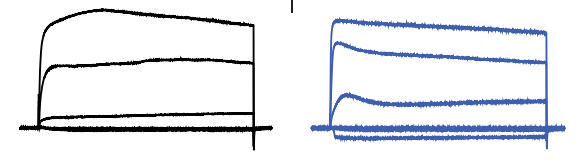

G

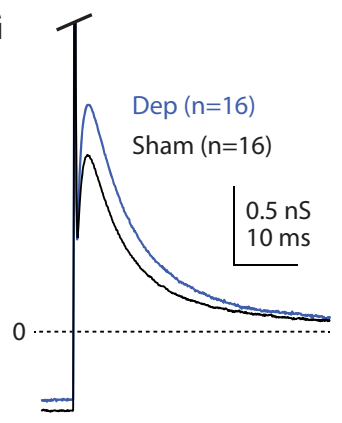

$\mathbf{E}$
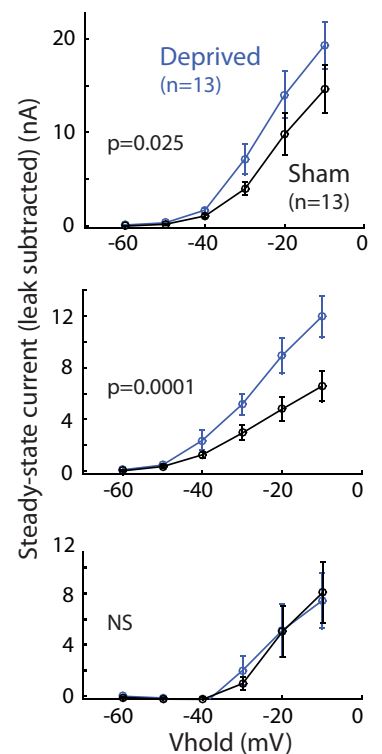

H

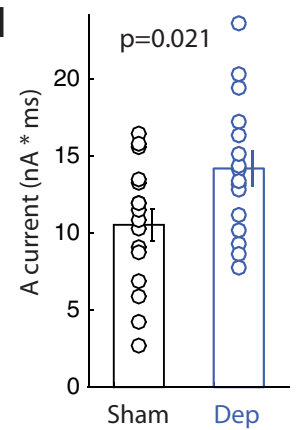

Figure 7. Deprivation upregulates voltage-activated $\mathrm{K}$ currents in L2/3 PV cells. $A$, Voltage-clamp protocol to measure delayed rectifier $\mathrm{K}$ currents, and example currents from one PV neuron in a sham mouse. SS, Steady-state current analysis window. B, I-V curve for SS and leak current for cells in $\boldsymbol{A}$. C, Leak conductance in sham and deprived cells, during baseline and DTX conditions. D, Mean current waveforms across sham and deprived PV cells at -60 to $-10 \mathrm{mV} V_{\text {hold }}$, measured at baseline and under DTX conditions (top and middle), and the calculated DTX-sensitive current (bottom). $\boldsymbol{E}, I-V$ plots for leak-subtracted steady-state current across cells, for each condition in $\boldsymbol{D}$. Pronounced currents activate at -40 to $-50 \mathrm{mV}$. The $p$ values are for sham vs deprived factor in two-way ANOVA. $F$, Voltage protocol for isolating $I_{A}$. $I_{A}$ was measured at $0 \mathrm{mV}$ by subtracting currents with a $-40 \mathrm{mV} 200 \mathrm{~ms}$ prestep (which inactivates $I_{A}$ ) from currents with a $-70 \mathrm{mV}$ preset (which does not inactivate $I_{A}$ ). Traces show an example cell. $G$, Mean $I_{A}$ waveform from sham and deprived cells. $\boldsymbol{H}, I_{A}$ magnitude (integrated over first $25 \mathrm{~ms}$ ) for sham and deprived cells. Each circle is one cell. Bars show the mean \pm SEM.

is common across sensory cortex. Optogenetic L4 stimulation showed that plasticity involves the L4-L2/3 feedforward microcircuit (Fig. 2). However, because L2/3 PV neurons are shared among feedforward, recurrent, and long-range projections, inhibition within all these circuits is likely to be reduced in L2/3 by whisker deprivation. Prior studies demonstrated plasticity on this $1 \mathrm{~d}$ timescale for inhibitory neuron axon/dendrite structure, inhibitory synapse number, and functional strength of PV input and output synapses (Knott et al., 2002; Maffei et al., 2006, 2010; Marik et al., 2010; Keck et al., 2011; Chen et al., 2012; van Versendaal et al., 2012; Chen and Nedivi, 2013; Kuhlman et al., 2013). Here we discovered equally rapid plasticity of PV intrinsic excitability. Thus, virtually every level of PV circuits exhibits rapid plasticity in response to sensory experience.

The cellular implementation of PV circuit plasticity appears to differ between cortical areas and with the duration of deprivation. In rat S1, sustained ( $\geq 5 \mathrm{~d}$ ) whisker deprivation weakens L4-L2/3 feedforward inhibition by weakening L4 excitatory input to fast-spiked (FS; presumed PV) neurons, with no change in FS intrinsic excitability (House et al., 2011). In mouse V1, $1 \mathrm{~d}$ of monocular deprivation similarly weakens L4-evoked excitatory synaptic input to PV neurons (Kuhlman et al., 2013). However, $1 \mathrm{~d}$ of whisker deprivation in mice changes neither net excitatory nor inhibitory synaptic input to PV neurons in S1, but instead reduces $\mathrm{PV}$ intrinsic excitability by increasing spike threshold (Figs. 4, 5, 6). Thus, PV circuits appear to use different plasticity mechanisms to achieve a similar overall reduction in circuit output. Our findings suggest that within S1, the most rapid mechanism for disinhibition in $\mathrm{L} 2 / 3$ is reduction in PV intrinsic excitability, followed more slowly by the weakening of L4 excitatory synapses onto PV neurons.

$\mathrm{PV}$ intrinsic excitability is plastic in response to strong or prolonged genetic or pharmacological suppression or enhancement of cortical activity (Miller et al., 2011; Dehorter et al., 2015) and epilepsy (Li et al., 2011). Our results show that this plasticity also occurs to natural variations in sensory use, and thus is a normally occurring, rapid plasticity mechanism in cortex. 

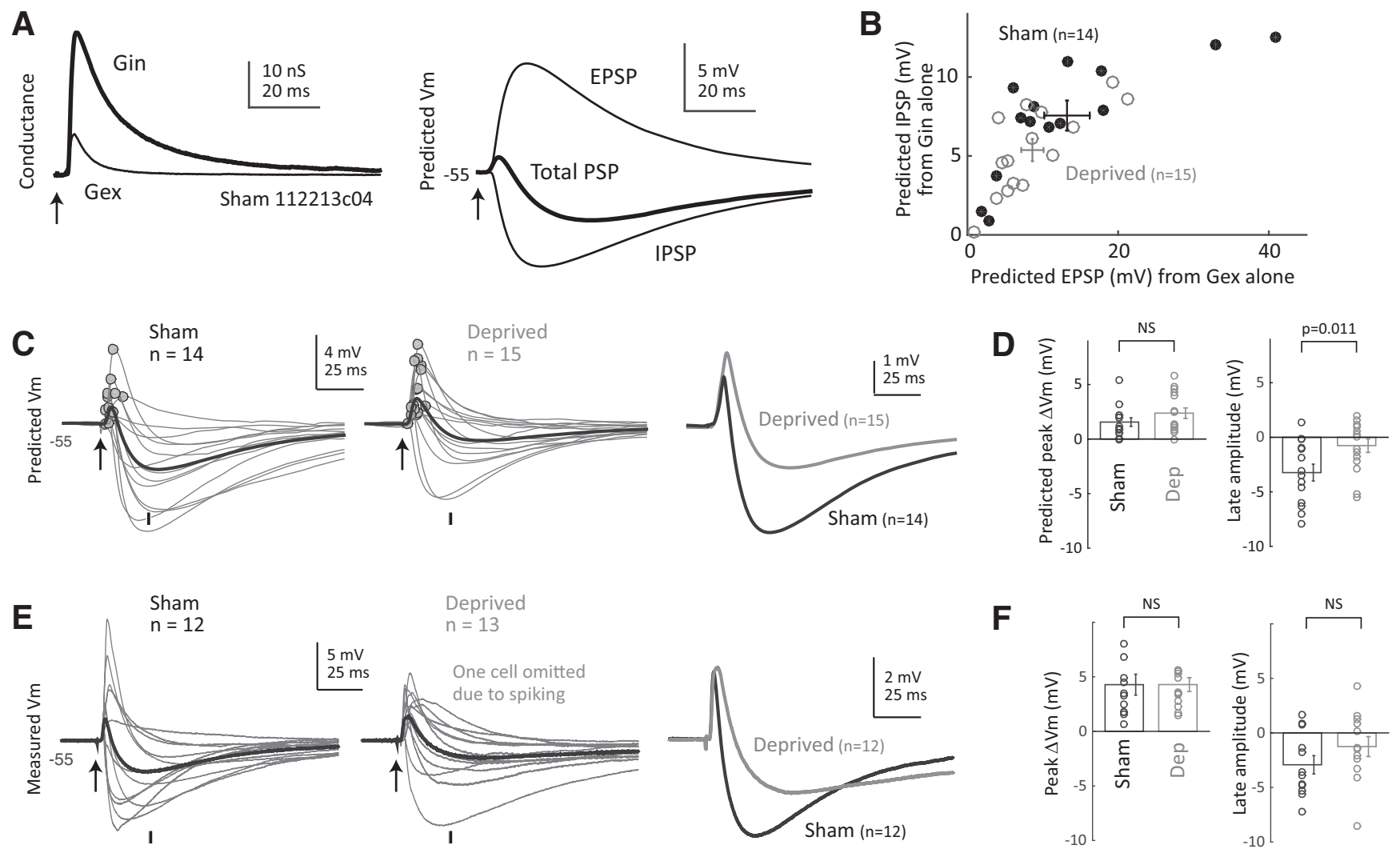

Figure 8. Changes in Gex and Gin are coordinated to maintain stable peak PSP amplitude in L2/3 PYR cells. A, Example neuron showing measured L4-evoked Gex and Gin conductance waveforms (left) and predicted PSPs from a baseline $V_{\mathrm{m}}$ of $-55 \mathrm{mV}$ (right). PSPs were predicted from Gex alone (EPSP), Gin alone (IPSP), or from both Gex and Gin together (total PSP). $\boldsymbol{B}$, Peak predicted EPSP (from Gex alone) and IPSP (from Gin alone) at 1.4 $\times E \theta$ in each sham and deprived cell from Figure 1. Error bars are the mean \pm SEM for sham and deprived populations. C, Predicted total PSP for each sham and deprived neuron, and population means (thick). Arrow, L4 stimulus. Dots, PSP peaks. Vertical tick, Analysis time for late inhibition. Right, Population mean PSPs calculated from peak-aligned PSPs in individual cells. D, Quantification of changes in predicted peak PSP and late inhibition following deprivation. E, Real L4-evoked PSPs measured in sham and deprived L2/3 PYR neurons from an estimated baseline synaptic $V_{m}$ of $-55 \mathrm{mV}$. Thick lines, Population means. One deprived cell was omitted because it spiked. Right, Population mean PSPs calculated from peak-aligned PSPs in individual cells. $\boldsymbol{F}$, Quantification of deprivation effects on peak PSP and late amplitude during the IPSP.

\section{Mechanism for altered PV intrinsic excitability}

Deprivation altered the intrinsic excitability of PV cells near spike threshold, but not at rest. Near-threshold excitability is strongly regulated in L2/3 PV neurons by low-threshold Kv1 delayed rectifier channels, which help set spike threshold and spike latency (Goldberg et al., 2008). Recent studies identified molecular pathways for slower activity-dependent regulation of Kv1 currents via the transcription factor Er81 (Dehorter et al., 2015) or by neuregulin (NRG1) signaling through its receptor ErbB4 (Li et al., 2011). Modulation of PV cell activity by direct genetic or pharmacological interventions (Dehorter et al., 2015), epilepsy (Li et al., 2011), or synaptic stimulation (Campanac et al., 2013) regulates Kv1 channels to alter near-threshold PV intrinsic excitability. Our results are consistent with this same mechanism occurring rapidly during sensory deprivation, because deprivation increased a voltage-activated sustained current that activated near spike threshold $(-40 \mathrm{mV})$, which is characteristic of Kv1 family channels (Fig. 7). The molecular identity of the channels that mediate this current remains unknown, but it likely involves a Kv1 family member that is not Kv1.1. Thus, we propose that activity-dependent modulation of Kv1 function, which was previously observed during artificial activity manipulation or epilepsy, is recruited with brief alterations of sensory experience to regulate PV circuit function.

Deprivation also increased $I_{\mathrm{A}}$ potassium values. Upregulation of $I_{\mathrm{A}}$ was suggested previously to occur in $\mathrm{L} 4$ fast-spiking neurons after prolonged ( $30 \mathrm{~d}$ ) whisker deprivation, and to cause elevated spike threshold and spike latency (Sun, 2009). We find that this occurs within $1 \mathrm{~d}$ of deprivation. Thus, multiple Kv channels are rapidly regulated in PV cells by whisker experience to change near-threshold but not resting excitability.

What signaling pathways mediate experience-dependent regulation of potassium channel function in PV neurons? This is unknown, but one candidate is NRG1/ErbB4 signaling, which controls many aspects of PV circuit development and plasticity (Mei and Nave, 2014). NRG1/ErbB4 is required for visual deprivation-induced weakening of PV circuits (Sun et al., 2016) and for epilepsy-dependent regulation of PV intrinsic excitability (Li et al., 2011).

\section{PV circuit weakening and sensory response homeostasis in $L 2 / 3$ of $S 1$}

Rapid weakening of PV circuits contributes to homeostatic stabilization of sensory-evoked spiking in L2/3 PYR cells, which was observed following brief reductions in whisker input. In classical whisker map plasticity, $\geq 5 \mathrm{~d}$ of D-row whisker deprivation weakens spiking to deprived whiskers in L2/3 PYR cells, mediated in part by long-term depression (LTD) at excitatory L4-L2/3 PYR synapses (Fox, 2002; Feldman, 2009). With briefer 1-3 d whisker deprivation, whisker-evoked spiking remains normal or is slightly increased, even though whisker-evoked synaptic excitation is already weakened in L2/3 PYR cells. This is due to a sub- 
stantial drop in whisker-evoked inhibition in L2/3 PYR cells, measured with whole-cell recording in vivo (Li et al., 2014). Our results identify the circuit loci for this plasticity within L4-L2/3 feedforward excitatory and inhibitory circuits. Deprivation weakens L4-L2/3 feedforward excitation onto PYR cells in $<1 \mathrm{~d}$ (Figs. 1, 2), as expected for a rapid LTD process, and similar to visual deprivation-induced LTD in L2/3 of V1 (Heynen et al., 2003). At the same time, L4-L2/3 feedforward inhibition is weakened more strongly, by rapid reduction in PV intrinsic excitability, and this precisely counteracts the loss of feedforward excitation onto L2/3 PYR cells, thus preserving L4-evoked PSPs (Fig. 8). The LTD and PV intrinsic excitability mechanisms operate within different neurons, and therefore must be coordinated to accurately stabilize L2/3 PYR synaptic and spiking responses, but how this is achieved is unknown.

We found that $1 \mathrm{~d}$ deprivation reduces feedforward Gin preferentially over Gex in L2/3 PYR cells, elevating E-I conductance ratio. Remarkably, this change in $E-I$ conductance ratio is appropriate to maintain stable feedforward PSP magnitude, for cells just below spike threshold (Fig. 8). This is because in this $V_{\mathrm{m}}$ regime, the driving force on inhibition is lower than the excitation, so a larger change is required in Gin than Gex to produce an equivalent change $\left(\Delta V_{\mathrm{m}}\right)$ in IPSP versus EPSP amplitude, which approximately sum to yield a stable PSP peak. Thus, rapid plasticity of L2/3 PV intrinsic excitability appears calibrated to homeostatically maintain stable feedforward synaptic responses in the L2/3 PYR network. This explains why whisker-evoked spiking responses in L2/3 remain largely stable following brief whisker deprivation in vivo (Li et al., 2014). Interestingly, while brief deprivation preserves short-latency whisker-evoked spiking in L2/3 in vivo, it modestly increases long-latency spikes and spike jitter (Li et al., 2014), which may reflect the modest broadening of the PSP peak or the loss of the late IPSP (Fig. 8). With longer ( $\geq 5 \mathrm{~d}$ ) deprivation, feedforward Gex and Gin are reduced equally in L2/3 PYR cells, which predicts a smaller feedforward net PSP (House et al., 2011). This may explain the loss of whisker-evoked spikes in L2/3 during classical map plasticity (Li et al., 2014).

Longer deprivation drives other mechanisms for activitydependent weakening of PV circuits, including the weakening of excitatory synaptic input to PV cells (House et al., 2011; Kuhlman et al., 2013; Sun et al., 2016) and the weakening of unitary PV $\rightarrow$ PYR output synapses (Xue et al., 2014). How different plasticity mechanisms are coordinated within PV circuits remains unclear.

Rapid disinhibition has several advantages as a mechanism for network homeostasis. It is faster than classical homeostatic synaptic scaling or homeostatic plasticity of PYR intrinsic excitability, which take 2-3 d to occur in vivo (Breton and Stuart, 2009; Lambo and Turrigiano, 2013; Gainey and Feldman, 2017). It is highly efficient, because plasticity in a single PV cell will regulate the firing rate in hundreds of local PYR cells (Packer and Yuste, 2011). It also does not require broad adjustment of synaptic strength at hundreds or thousands of excitatory input synapses onto PV cells (Sun et al., 2016). We speculate that global adjustment of PV circuit gain by the regulation of PV intrinsic excitability may provide coarse regulation of excitation-inhibition balance, which is followed by slower, more precise adjustment of unitary PV $\rightarrow$ PYR synapses for target cell-specific regulation (Xue et al., 2014). Vasoactive intestinal peptide (VIP) interneuron circuits provide even faster, dynamic disinhibition (timescale of seconds), but whether these circuits are plastic in response to experience is unknown (Fu et al., 2015).

While reduced PV intrinsic excitability preserves the net feedforward PSP peak, the late IPSP component shows a strong ten- dency to be reduced (Fig. 8). This suggests that while PV circuit plasticity promotes stable synaptic responses to sparse, lowfrequency input (which is the dominant activity regime in L2/3 of S1; Barth and Poulet, 2012), it may also result in increased depolarization in L2/3 PYR cells during high-frequency input trains due to enhanced temporal summation. This may facilitate longterm potentiation and Hebbian map reorganization (Kuhlman et al., 2013; Gambino et al., 2014), similar to VIP-mediated disinhibition on short timescales (Williams and Holtmaat, 2018).

Note Added in Proof: The labels and colors for Sham and Deprived groups were inadvertently switched in Panel J of Figure 6 in the Early Release version published April 20, 2018. The figure has now been corrected.

\section{References}

Adesnik H, Scanziani M (2010) Lateral competition for cortical space by layer-specific horizontal circuits. Nature 464:1155-1160. CrossRef Medline

Allen CB, Celikel T, Feldman DE (2003) Long-term depression induced by sensory deprivation during cortical map plasticity in vivo. Nat Neurosci 6:291-299. CrossRef Medline

Barnes SJ, Sammons RP, Jacobsen RI, Mackie J, Keller GB, Keck T (2015) Subnetwork-specific homeostatic plasticity in mouse visual cortex in vivo. Neuron 86:1290-1303. CrossRef Medline

Barth AL, Poulet JF (2012) Experimental evidence for sparse firing in the neocortex. Trends Neurosci 35:345-355. CrossRef Medline

Breton JD, Stuart GJ (2009) Loss of sensory input increases the intrinsic excitability of layer 5 pyramidal neurons in rat barrel cortex. J Physiol 587:5107-5119. CrossRef Medline

Campanac E, Gasselin C, Baude A, Rama S, Ankri N, Debanne D (2013) Enhanced intrinsic excitability in basket cells maintains excitatory-inhibitory balance in hippocampal circuits. Neuron 77:712-722. CrossRef Medline

Chen JL, Nedivi E (2013) Highly specific structural plasticity of inhibitory circuits in the adult neocortex. Neuroscientist 19:384-393. CrossRef Medline

Chen JL, Villa KL, Cha JW, So PT, Kubota Y, Nedivi E (2012) Clustered dynamics of inhibitory synapses and dendritic spines in the adult neocortex. Neuron 74:361-373. CrossRef Medline

Coetzee WA, Amarillo Y, Chiu J, Chow A, Lau D, McCormack T, Moreno H, Nadal MS, Ozaita A, Pountney D, Saganich M, Vega-Saenz de Miera E, Rudy B (1999) Molecular diversity of K+ channels. Ann N Y Acad Sci 868:233-285. CrossRef Medline

Dehorter N, Ciceri G, Bartolini G, Lim L, del Pino I, Marín O (2015) Tuning of fast-spiking interneuron properties by an activity-dependent transcriptional switch. Science 349:1216-1220. CrossRef Medline

Donato F, Rompani SB, Caroni P (2013) Parvalbumin-expressing basketcell network plasticity induced by experience regulates adult learning. Nature 504:272-276. CrossRef Medline

Feldman DE (2009) Synaptic mechanisms for plasticity in neocortex. Annu Rev Neurosci 32:33-55. CrossRef Medline

Finnerty GT, Roberts LS, Connors BW (1999) Sensory experience modifies the short-term dynamics of neocortical synapses. Nature 400:367-371. CrossRef Medline

Fox K (2002) Anatomical pathways and molecular mechanisms for plasticity in the barrel cortex. Neuroscience 111:799-814. CrossRef Medline

Fritschy JM, Panzanelli P (2014) GABAA receptors and plasticity of inhibitory neurotransmission in the central nervous system. Eur J Neurosci 39:1845-1865. CrossRef Medline

Froemke RC (2015) Plasticity of cortical excitatory-inhibitory balance. Annu Rev Neurosci 38:195-219. CrossRef Medline

Fu Y, Kaneko M, Tang Y, Alvarez-Buylla A, Stryker MP (2015) A cortical disinhibitory circuit for enhancing adult plasticity. Elife 4:e05558. CrossRef Medline

Gabernet L, Jadhav SP, Feldman DE, Carandini M, Scanziani M (2005) Somatosensory integration controlled by dynamic thalamocortical feedforward inhibition. Neuron 48:315-327. CrossRef Medline

Gainey MA, Feldman DE (2017) Multiple shared mechanisms for homeostatic plasticity in rodent somatosensory and visual cortex. Philos Trans R Soc Lond B Biol Sci 372:20160157. CrossRef Medline

Gambino F, Holtmaat A (2012) Spike-timing-dependent potentiation of sensory surround in the somatosensory cortex is facilitated by 
deprivation-mediated disinhibition. Neuron 75:490-502. CrossRef Medline

Gambino F, Pagès S, Kehayas V, Baptista D, Tatti R, Carleton A, Holtmaat A (2014) Sensory-evoked LTP driven by dendritic plateau potentials in vivo. Nature 515:116-119. CrossRef Medline

Gibson JR, Beierlein M, Connors BW (1999) Two networks of electrically coupled inhibitory neurons in neocortex. Nature 402:75-79. CrossRef Medline

Goldberg EM, Clark BD, Zagha E, Nahmani M, Erisir A, Rudy B (2008) K+ channels at the axon initial segment dampen near-threshold excitability of neocortical fast-spiking GABAergic interneurons. Neuron 58:387-400. CrossRef Medline

Guan D, Horton LR, Armstrong WE, Foehring RC (2011) Postnatal development of A-type and Kv1- and Kv2-mediated potassium channel currents in neocortical pyramidal neurons. J Neurophysiol 105:2976-2988. CrossRef Medline

Gutman GA, Chandy KG, Grissmer S, Lazdunski M, McKinnon D, Pardo LA, Robertson GA, Rudy B, Sanguinetti MC, Stühmer W, Wang X (2005) International union of pharmacology. LIII. nomenclature and molecular relationships of voltage-gated potassium channels. Pharmacol Rev 57: 473-508. CrossRef Medline

Helmstaedter M, Staiger JF, Sakmann B, Feldmeyer D (2008) Efficient recruitment of layer $2 / 3$ interneurons by layer 4 input in single columns of rat somatosensory cortex. J Neurosci 28:8273-8284. CrossRef Medline

Hengen KB, Lambo ME, Van Hooser SD, Katz DB, Turrigiano GG (2013) Firing rate homeostasis in visual cortex of freely behaving rodents. Neuron 80:335-342. CrossRef Medline

Heynen AJ, Yoon BJ, Liu CH, Chung HJ, Huganir RL, Bear MF (2003) Molecular mechanism for loss of visual cortical responsiveness following brief monocular deprivation. Nat Neurosci 6:854-862. CrossRef Medline

Hippenmeyer S, Vrieseling E, Sigrist M, Portmann T, Laengle C, Ladle DR, Arber S (2005) A developmental switch in the response of DRG neurons to ETS transcription factor signaling. PLoS Biol 3:e159. CrossRef Medline

House DR, Elstrott J, Koh E, Chung J, Feldman DE (2011) Parallel regulation of feedforward inhibition and excitation during whisker map plasticity. Neuron 72:819-831. CrossRef Medline

Jiao Y, Zhang C, Yanagawa Y, Sun QQ (2006) Major effects of sensory experiences on the neocortical inhibitory circuits. J Neurosci 26:8691-8701. CrossRef Medline

Kätzel D, Zemelman BV, Buetfering C, Wölfel M, Miesenböck G (2011) The columnar and laminar organization of inhibitory connections to neocortical excitatory cells. Nat Neurosci 14:100-107. CrossRef Medline

Keck T, Scheuss V, Jacobsen RI, Wierenga CJ, Eysel UT, Bonhoeffer T, Hübener M (2011) Loss of sensory input causes rapid structural changes of inhibitory neurons in adult mouse visual cortex. Neuron 71:869-882. CrossRef Medline

Knott GW, Quairiaux C, Genoud C, Welker E (2002) Formation of dendritic spines with GABAergic synapses induced by whisker stimulation in adult mice. Neuron 34:265-273. CrossRef Medline

Kuhlman SJ, Olivas ND, Tring E, Ikrar T, Xu X, Trachtenberg JT (2013) A disinhibitory microcircuit initiates critical-period plasticity in the visual cortex. Nature 501:543-546. CrossRef Medline

Lambo ME, Turrigiano GG (2013) Synaptic and intrinsic homeostatic mechanisms cooperate to increase L2/3 pyramidal neuron excitability during a late phase of critical period plasticity. J Neurosci 33:8810-8819. CrossRef Medline

Li KX, Lu YM, Xu ZH, Zhang J, Zhu JM, Zhang JM, Cao SX, Chen XJ, Chen Z, Luo JH, Duan S, Li XM (2011) Neuregulin 1 regulates excitability of fast-spiking neurons through Kv1.1 and acts in epilepsy. Nat Neurosci 15:267-273. CrossRef Medline

Li L, Gainey MA, Goldbeck JE, Feldman DE (2014) Rapid homeostasis by disinhibition during whisker map plasticity. Proc Natl Acad Sci U S A 111:1616-1621. CrossRef Medline

Madisen L, Zwingman TA, Sunkin SM, Oh SW, Zariwala HA, Gu H, Ng LL, Palmiter RD, Hawrylycz MJ, Jones AR, Lein ES, Zeng H (2010) A robust and high-throughput cre reporting and characterization system for the whole mouse brain. Nat Neurosci 13:133-140. CrossRef Medline

Maffei A, Nelson SB, Turrigiano GG (2004) Selective reconfiguration of layer 4 visual cortical circuitry by visual deprivation. Nat Neurosci 7:1353-1359. CrossRef Medline

Maffei A, Nataraj K, Nelson SB, Turrigiano GG (2006) Potentiation of cortical inhibition by visual deprivation. Nature 443:81-84. CrossRef Medline

Maffei A, Lambo ME, Turrigiano GG (2010) Critical period for inhibitory plasticity in rodent binocular V1. J Neurosci 30:3304-3309. CrossRef Medline

Marik SA, Yamahachi H, McManus JN, Szabo G, Gilbert CD (2010) Axonal dynamics of excitatory and inhibitory neurons in somatosensory cortex. PLoS Biol 8:e1000395. CrossRef Medline

Mateo C, Avermann M, Gentet LJ, Zhang F, Deisseroth K, Petersen CC (2011) In vivo optogenetic stimulation of neocortical excitatory neurons drives brain-state-dependent inhibition. Curr Biol 21:1593-1602. CrossRef Medline

Mei L, Nave KA (2014) Neuregulin-ERBB signaling in the nervous system and neuropsychiatric diseases. Neuron 83:27-49. CrossRef Medline

Miller MN, Okaty BW, Kato S, Nelson SB (2011) Activity-dependent changes in the firing properties of neocortical fast-spiking interneurons in the absence of large changes in gene expression. Dev Neurobiol 71:62-70. CrossRef Medline

Packer AM, Yuste R (2011) Dense, unspecific connectivity of neocortical parvalbumin-positive interneurons: a canonical microcircuit for inhibition? J Neurosci 31:13260-13271. CrossRef Medline

Pouille F, Scanziani M (2001) Enforcement of temporal fidelity in pyramidal cells by somatic feed-forward inhibition. Science 293:1159-1163. CrossRef Medline

Resnik J, Polley DB (2017) Fast-spiking GABA circuit dynamics in the auditory cortex predict recovery of sensory processing following peripheral nerve damage. Elife 6:e21452. CrossRef Medline

Robertson B, Owen D, Stow J, Butler C, Newland C (1996) Novel effects of dendrotoxin homologues on subtypes of mammalian Kv1 potassium channels expressed in xenopus oocytes. FEBS Lett 383:26-30. CrossRef Medline

Shao YR, Isett BR, Miyashita T, Chung J, Pourzia O, Gasperini RJ, Feldman DE (2013) Plasticity of recurrent $12 / 3$ inhibition and gamma oscillations by whisker experience. Neuron 80:210-222. CrossRef Medline

Shen W, Hernandez-Lopez S, Tkatch T, Held JE, Surmeier DJ (2004) Kv1.2containing $\mathrm{K}+$ channels regulate subthreshold excitability of striatal medium spiny neurons. J Neurophysiol 91:1337-1349. CrossRef Medline

Shepherd GM, Pologruto TA, Svoboda K (2003) Circuit analysis of experience-dependent plasticity in the developing rat barrel cortex. Neuron 38:277-289. CrossRef Medline

Sun QQ (2009) Experience-dependent intrinsic plasticity in interneurons of barrel cortex layer IV. J Neurophysiol 102:2955-2973. CrossRef Medline

Sun Y, Ikrar T, Davis MF, Gong N, Zheng X, Luo ZD, Lai C, Mei L, Holmes TC, Gandhi SP, Xu X (2016) Neuregulin-1/ErbB4 signaling regulates visual cortical plasticity. Neuron 92:160-173. CrossRef Medline

Turrigiano GG (2017) The dialectic of Hebb and homeostasis. Philos Trans R Soc Lond B Biol Sci 372:20160258. CrossRef Medline

van Versendaal D, Rajendran R, Saiepour MH, Klooster J, Smit-Rigter L, Sommeijer JP, De Zeeuw CI, Hofer SB, Heimel JA, Levelt CN (2012) Elimination of inhibitory synapses is a major component of adult ocular dominance plasticity. Neuron 74:374-383. CrossRef Medline

Wang FC, Bell N, Reid P, Smith LA, McIntosh P, Robertson B, Dolly JO (1999) Identification of residues in dendrotoxin $\mathrm{K}$ responsible for its discrimination between neuronal $\mathrm{K}+$ channels containing Kv1.1 and 1.2 alpha subunits. Eur J Biochem 263:222-229. CrossRef Medline

Wehr M,Zador AM (2003) Balanced inhibition underlies tuning and sharpens spike timing in auditory cortex. Nature 426:442-446. CrossRef Medline

Williams LE, Holtmaat A (2018) Higher-order thalamocortical inputs gate synaptic long-term potentiation via disinhibition. bioRxiv. Advance online publication. Retrieved April 21, 2018. doi:10.1101/281477. CrossRef

Xue M, Atallah BV, Scanziani M (2014) Equalizing excitation-inhibition ratios across visual cortical neurons. Nature 511:596-600. CrossRef Medline 